\title{
Age-Dependent Specification of the Corticocortical Connections of Cerebral Grafts
}

\author{
Mary F. Barbe ${ }^{1}$ and Pat Levitt ${ }^{2}$ \\ 'Department of Physical Therapy, Temple University, Philadelphia, Pennsylvania 19140 and ${ }^{2}$ Department of \\ Neuroscience and Cell Biology, UMDNJ, Robertwood Johnson Medical School, Piscataway, New Jersey 08854
}

To investigate further the factors involved in the development of cerebral cortical circuitry, we examined the organization of corticocortical connections of heterotopic grafts of fetal cortex placed into neonatal rat cortices. Presumptive perirhinal or sensorimotor areas of the cerebral wall were removed as slabs from embryonic day 12 (E12), E13, or E14 rats and transplanted heterotopically into either rostral perirhinal or sensorimotor cortical areas of neonatal rats. Two weeks later, the afferent cortical connections of the grafts were labeled by placing DilC $_{18}-3$ (Dil) into each transplant site. Both the E12 and E13 heterotopic transplants of presumptive perirhinal cortex contain mostly precursor cells. When these grafts are placed into sensorimotor cortex, callosal connections are formed primarily with the contralateral sensorimotor $(\mathrm{Sml})$ area, the normal projection of Sml cortex. In contrast, the E14 heterotopic transplants of the perirhinal cortical wall, containing many more postmitotic neurons, developed contralateral connections with both sensorimotor and rostral perirhinal cortices. Thus, when precursor cells are transplanted heterotopically, by using E12/E13 donor tissue, the grafts receive projections that are similar to those of the host cortical area. When older cortical neurons, together with precursors, are transplanted into a heterotopic cortical area, by using E14 donor tissue, their cortical connections exhibit both host and original donor phenotypes. The data are consistent with our previous analysis of thalamocortical connections of grafts (Barbe and Levitt, 1992b) and suggest the existence of a cell-cell recognition system for thalamocortical and corticocortical circuit formation, whose mechanisms of action may be linked to the timing of neurogenesis.

[Key words: neural graft, sensorimotor cortex, perirhinal cortex, cell fate, cell specification, and cortical connections]

The cerebral cortex is organized into separate areas based on anatomical, neurochemical and functional differences. The precise organization of the cortex is achieved by the progressive steps of neurogenesis, migration of neurons to specific laminae

\footnotetext{
Received Feb. 28, 1994, revised June 30, 1994; accepted Aug. 22, 1994.

We are grateful to Dr. K. Eagleson for critical reading of the manuscript. This work was supported by NSF Grant 9209459 and Temple University Grants to M.F.B. and NIMH Grant MH45507 to P.L.

Correspondence should be addressed to Dr. Mary Frances Barbe, Department of Physical Therapy, College of Allied Health. Temple University, 3307 North Broad Street, Philadelphia, PA 19140.

Copyright (C) 1995 Society for Neuroscience 0270-6474/95/151819-16\$05.00/0
}

and axon elongation to appropriate targets. The time of origin of a neuron correlates strongly with both a neuron's final laminar position (McConnell, 1988; McConnell and Kaznowski, 1991) and its axonal connections (Caviness and Rakic, 1978; Lemmon and Pearlman, 1981; Jensen and Killackey, 1984; Katz, 1991; Schwartz et al., 1991). Although the mechanisms underlying the determination of the final pattern of cortical connections are unknown, the formation of specific projection patterns are probably based on a large number of factors, including molecular interactions that control laminar fate via local neuroepithelial factors (McConnell and Kaznowski, 1991), axonal guidance by pioneer axons (McConnell et al., 1989; Ghosh et al., 1990; Ghosh and Shatz, 1993), transient targeting (Stanfield and O'Leary, 1988), local positional cues (Fraser, 1980; Gierer, 1987; Walter et al., 1987; Harris, 1989; Stahl et al., 1990; Simon and O'Leary, 1992a, 1992b), diffusible factors used as intermediate guideposts (Tessier-Lavigne et al., 1988; Placzek et al., 1990), target chemotrophic and chemotropic molecules (Lumsden and Davies, 1983; Hankin and Lund, 1987; Heffner et al., 1990; Yamamoto et al., 1989, 1992; O'Leary et al., 1990; Baier and Bonhoeffer, 1992), chemoaffinity molecules (Sperry, 1963; Levitt, 1984), and selective elimination of temporary axonal projections (Stanfield et al., 1982, 1987; Chalupa and Killackey, 1989; O'Leary and Stanfield, 1989; Callaway and Katz, 1990).

Recent transplantation studies of cortical tissue have demonstrated an early commitment of neurons to express a specific molecular phenotype. In these experiments, the expression of the limbic system-associated membrane protein (LAMP), a marker of limbic cortex (Levitt, 1984; Horton and Levitt, 1988), was regulated in a complex fashion (Barbe and Levitt, 1991, 1992b). LAMP is a new member of the Ig-superfamily (Pimenta et al., 1993) and mediates adhesive interactions (Zhukareva and Levitt, 1993) that may be critical for the formation of some limbic circuits (Keller et al., 1989; Barbe and Levitt, 1992a). We found that there is a critical period for the specification of cortical neurons to express this molecular phenotype. Donor tissue from either LAMP-positive perirhinal or LAMP-negative sensorimotor regions, harvested at $\mathrm{E} 12$, when all cells are precursors, exhibit molecular features of the host milieu after grafting. Older grafts (E14 or E17), which have increasing proportions of postmitotic neurons, contain increasing numbers of neurons expressing a molecular phenotype faithful to their donor origin (Barbe and Levitt, 1991). Results of a second study suggest that this molecular specification correlates strongly with the thalamocortical connections of the grafted tissue (Barbe and Levitt, 1992b). 
Figure 1. Cytoarchitectural maps of the lateral (left) and medial (right) aspects of the cerebral cortical hemisphere, redrawn from Vogt and Miller (1981), Deacon et al. (1983), and Ziles et al., (1980), Paxinos and Watson (1986). $F L$, sensory and motor forelimb overlap area; $H L$, sensory and motor hindlimb overlap area. For other abbreviations, see Appendix.
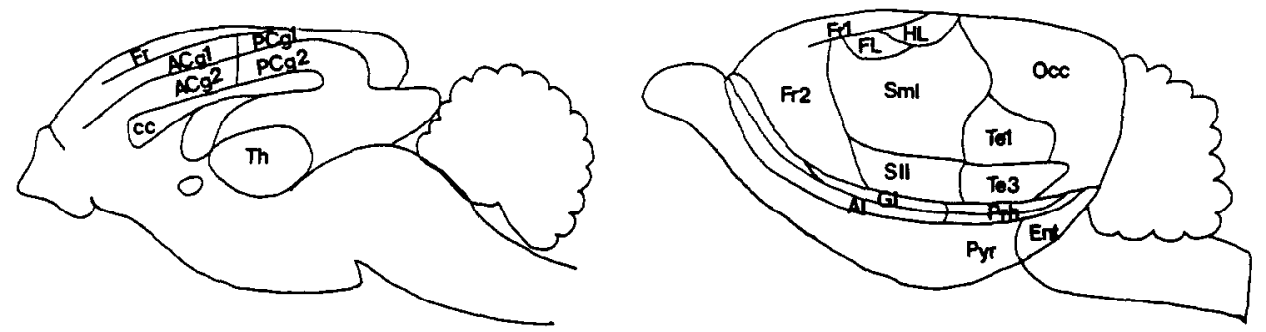

In the present study, we have examined the pattern of ipsilateral and callosal projections into perirhinal and sensorimotor grafts from the host cortex. The experiments were designed to further investigate our hypothesis that certain phenotypic traits of neurons are specified early, and that the molecular phenotype of the neurons may help determine synaptic connections. Our present transplantation results show that the E14 heterotopically located perirhinal grafts form hybrid cortical connections that reflected both their donor origin and their new host locale, while E13 and E12 grafts form connections that reflect mostly their new host position.

\section{Materials and Methods}

Transplantation of fetal tissue to neonatal hosts. Fetal Sprague-Dawley rats (Harlan) were obtained from timed-pregnant dams. Plug date is considered to be E0. Dams were anesthetized with Nembutal $(50 \mathrm{mg} /$ $\mathrm{kg}$ body weight), and animals at embryonic day (E) 12,13 , and 14 were removed. Areas of the cerebral wall containing presumptive perirhinal and sensorimotor cortices were excised and prepared as described previously (Barbe and Levitt, 1991, 1992b). E12 and E14 correspond respectively to times before and after neurons initiate their commitment to the limbic molecular phenotype (Barbe and Levitt, 1991). Slabs of tissue were dissected out in ice-cold $\mathrm{F} 12$ media (GIBCO-Bethesda Research Labs, Gaithersburg, MD) with $6.5 \mathrm{mg} / \mathrm{ml}$ glucose, labeled with $0.002 \%$ fast blue (Sigma, St. Louis, MO) in media, rinsed and transplanted into newborn (PO) host rat pups, a time when corticocortical projections are still developing (Wise and Jones 1976, 1978; Ivy et al., 1979; Valentino and Jones, 1982; Hernit et al., 1990; Elberger, 1994). Transplants were placed heterotopically or homotopically into either sensorimotor or perirhinal cortex. Grafts into the sensorimotor cortex were placed in the rostral SmI area at the level of the septal end of the hippocampus. Grafts into the perirhinal cortex were placed into area 35 , just caudal to the claustrum. Eighteen to 20 animals were grafted per group, totaling 151 animals. Two weeks after surgery, rat pups were perfused with $4 \%$ paraformaldehyde in $0.1 \mathrm{M}$ sodium phosphate buffer ( $\mathrm{pH}$ 7.4). Brains were removed from the skull and postfixed by immersion for 24 hr. Control animals that had not received any transplants were also fixed for DiI labeling (see below).

Labeling with Dil. In order to examine the cortical connections of the transplant, a lipophilic fluorescent tracer, DiIC ${ }_{18}-(3)$ [DiI; 1,1'-dioctadecyl-3,3,3'3'-tetramethylindocarbocyanine perchlorate (Molecular Probes, Eugene, OR); Godement et al.,1987], was inserted into the transplants or the identical areas of controls in the fixed brains to retrogradely label cortical neurons innervating the graft (efferent axons were also labeled but were not quantitated). The DiI was dissolved in $100 \%$ ethanol, precipitated by evaporation onto small pieces of pulled glass micropipettes and inserted into the transplant sites of the fixed brains. The DiI was also inserted into either the rostral Prh or SmI in age-matched nontransplanted control animals $(n=4$ /group). Care was taken to keep the coated glass piece within the cortical wall itself without penetrating the underlying white matter. Brains were incubated at $37^{\circ} \mathrm{C}$ for $8-9$ weeks in $4 \%$ paraformaldehyde fixative in $0.1 \mathrm{M}$ sodium phosphate buffer, and were then sectioned on a vibratome into $200 \mu \mathrm{m}$ coronal slices. The sections were wet mounted onto slides and coverslipped with $80 \%$ glycerol in $0.1 \mathrm{M}$ phosphate buffer. Fast blue and DiI at the transplant site were photographed, the coverslip removed and the sections counterstained with $m$-phenylenediamine in glycerol/phosphate buffer (Quinn and Webber, 1988). The sections were reexamined for integrity of the transplant, insertion site and depth of the DiI label in the transplant, the location of fibers extending from the grafts and location of retrogradely labeled neurons within the cortex.
Cytoarchitectural mapping and quantification. Only those brains with both well-integrated transplants and a DiI insertion site limited to the boundaries of the transplant (micropipette placed directly into the transplant site and glass not penetrating white matter) were used for analysis. While approximately $85 \%$ of the grafts survived well, only approximately $25 \%$ of the labeled grafts met both stringent criteria $(n=3-7$ per group). Labeled neurons were mapped according to laminar and area location in sequential coronal sections and were plotted onto maps depicting the entire medial and lateral surfaces of the cercbral hemisphere. The statistical differences between the mean number retrogradely labeled neurons in the areal locations of each experimental and control groups were evaluated with an analysis of variance procedure (ANOVA) followed by a Fisher PLSD test for significance. Additionally, the regions analyzed were categorized into groups based on the retrograde labeling patterns of the normal, nontransplanted brains: those regions that projected exclusively to the nontransplanted rostral perirhinal cortex, those regions that projected exclusively to the nontransplanted sensorimotor cortex, those regions that projected to both perirhinal and sensorimotor cortices in the nontransplanted animals. An additional category in the experimental animals included those cortical regions that contained retrogradely labeled neurons in the grafted brains only. The number of labeled neurons in each of these category was compared using an $\Lambda$ NOVA, as was the variance overall.

Figure 1 presents the medial and lateral surface reconstructions of cytoarchitectural parcellations of the different cortices employed throughout this study. Neocortical areas are delineated according to Ziles $(1985,1990)$ and Ziles and Wree (1985), Paxinos and Watson (1986), and Paxinos et al. (1991). In the following descriptions, SmI will be used to designate the first somatic sensory area, an area that includes part of the sensory-motor overlap zone (Hall and Lindholm, 1974; Donoghue et al., 1979, 1982; Sanderson et al., 1984). The term anterior cingulate cortex $(\mathrm{ACg})$ refers to the anterior half of medial cortex composed of areas infraradiata $(\mathrm{ACg} 2)$ and precentralis agranularis (ACg1) designated area 24 (Rose, 1929; Krieg, 1946; Guildin and Markowitsch, 1983), while posterior cingulate cortex (PCg; areas 23 and 29) refers to the posterior half of the medial cortex composed of areas retrosplenialis (PCg2) and agranularis (PCg1) (Rose, 1929; Krieg, 1946; Vogt and Miller, 1981; Guildin and Markowitsch, 1983; Ziles et al., 1986). Limbic areas were mapped according to criteria of Cechetto and Saper for the divisions of the insular association cortex as designated in the atlas by Paxinos and Watson (1986) and Guildin and Markowitsch (1983). The insular cortex (area 13), also known as the claustrocortex (Ziles et al., 1980), can be divided into agranular (Al) and granular (GI) portions (Guildin and Markowitsch, 1983). Posterior to the insular cortex is the perirhinal cortex (area 35; Kretteck and Price, 1977; Ziles et al., 1980; Bayer, 1990), located just below the auditory cortex $(\mathrm{Te} 1, \mathrm{Te} 3)$. The transplants in this study that were placed into perirhinal cortex (Prh or P) were placed into the rostral part of area 35. Cell plots were done in the all cortical areas between $0.20 \mathrm{~mm}$ rostral to bregma and $7.80 \mathrm{~mm}$ caudal from bregma. Cortical areas analyzed but not represented in Tables 1 and 2 are frontal motor area 1 (Frl; area 1 of Kreig's 1946 map) cortex rostral to $0.2 \mathrm{~mm}$ rostral to bregma, frontal area $2(\mathrm{Fr} 2)$, prepiriform cortex (pyr), dorsal endopiriform, ipsilateral forelimb (FL; DiI too dense), and entorhinal cortices. These latter areas with the exception of the ipsilateral FL were not included in the tables because the number of retrogradely labeled neurons present in these regions were very low to absent.

\section{Results}

Transplants were well incorporated within the host cortex. Fast blue labeling of the grafted cells allowed the determination of whether the DiI was placed within the graft site. Insertion of DiI 
Table 1. Mean number of retrogradely labeled neurons present in the ipsilateral cortical areas analyzed following DiI labeling in the transplant or indicated area ( $n=3-7$ per group)

\begin{tabular}{|c|c|c|c|c|c|c|c|c|c|c|c|c|c|c|c|c|c|}
\hline \multirow[b]{2}{*}{ Group } & \multicolumn{4}{|c|}{$\begin{array}{l}\text { Regions that project } \\
\text { into Normal } \mathrm{P}^{a} \text { only }\end{array}$} & \multicolumn{5}{|c|}{$\begin{array}{l}\text { Regions that project } \\
\text { into both } \mathrm{P} \text { and } \mathrm{Sm}\end{array}$} & \multicolumn{4}{|c|}{$\begin{array}{l}\text { Regions that project } \\
\text { into Normal Sm only }\end{array}$} & \multicolumn{3}{|c|}{ Graft-dependent inputs } & \multirow{2}{*}{$\begin{array}{l}\text { Total of } \\
\text { category } \\
\text { (means) }\end{array}$} \\
\hline & $\overline{\mathrm{ACg}}$ & AI & Prh & Mean $^{b}$ & $\overline{\text { Frl }}$ & $\mathrm{HL}$ & $\mathrm{SmI}$ & SII & Mcan & $\mathrm{Te} 1$ & $\mathrm{Te} 3$ & Oc & Mcan & $\overline{\mathrm{PCg}}$ & GI & Mean & \\
\hline Normal $\mathbf{P}^{a}$ & 17 & 10 & $30^{d}$ & $23.2 *$ & 3 & 23 & 105 & 98 & 57.2 & 0 & 0 & 0 & $0^{*}$ & 0 & 0 & 0 & 80.4 \\
\hline $\mathbf{P} \rightarrow \mathbf{P}$ & 5 & $25 \phi^{*}$ & $31^{d}$ & $20.1^{*}$ & 11 & 43 & 116 & 84.3 & 63.5 & 5.5 & 2.75 & $0^{*}$ & 10.6 & 3 & $23.5 \phi^{*}$ & $13.8 \phi^{*}$ & 108 \\
\hline $\mathrm{E} 12 \mathrm{Sm} \rightarrow \mathrm{P}$ & 2 & 14.5 & $62^{d}$ & $34.3^{*}$ & 0 & $1 *$ & 30.5 & 77 & $26.6^{* *}$ & 34 & 5.5 & $0^{*}$ & 12.6 & 0 & 10 & $4.8^{*}$ & 78.3 \\
\hline Normal Sm & 0.5 & 0 & 0 & $0.17 \phi$ & 56 & 68 & $162^{e}$ & 63 & 87 & 8 & 0.8 & $30 \phi$ & $13.1 \phi$ & 0 & 0 & 0 & 100.3 \\
\hline $\mathrm{Sm} \rightarrow \mathrm{Sm}$ & 0 & 0 & 13.3 & $4.4 \phi$ & 15 & 13.6 & $181^{e}$ & 22 & 51 & 3 & 0 & $23 \phi$ & 6 & 0 & 0 & 0 & 61.4 \\
\hline $\mathrm{E} 14 \mathrm{P} \rightarrow \mathrm{Sm}$ & $13 *$ & 2.4 & $54.8 *$ & $23.5^{*}$ & $71.6 \phi$ & 33 & $202^{e}$ & 156 & $112.3 \phi$ & 57.7 & $29 * \phi$ & 20.1 & $35.6 * \phi$ & $25^{*} \phi$ & 7 & $16.1 * \phi$ & 187.5 \\
\hline $\mathrm{E} 13 \mathrm{P} \rightarrow \mathrm{Sm}$ & 0 & 0 & 1.3 & $0.4 \phi$ & 7.7 & 10.7 & $101^{e}$ & 31 & 37.8 & 1 & 3 & $0^{*}$ & 1.1 & 0 & 0 & 0 & 39.3 \\
\hline $\mathrm{E} 12 \mathrm{P} \rightarrow \mathrm{Sm}$ & 2 & 0 & 0 & $0.6 \phi$ & 49.5 & $1.3 *$ & $107^{e}$ & 31 & 47.1 & 25 & 18.3 & $36.7 \phi$ & $26.9 \phi$ & 0 & 0 & 0 & 74.6 \\
\hline
\end{tabular}

a DiI was inserted into rostral perirhinal cortex only in age-matched nontransplanted animals.

${ }^{b}$ Mean number of retrogradely labeled neurons in category.

' Refers to caudal frontal cortex, area 1 only, an area directly lateral to ACg, medial to FL.

${ }^{d}$ Retrogradely labeled neurons are located caudal to transplant of DiI insertion site in rostral Prh cortex.

" Retrogradely labeled neurons are located in SmI area both rostral and caudal to transplant of Dil insertion site.

* Group differs from Normal $S, 0.05>p \leq 0.001$.

** Group differs from Normal $S, p=0.05$.

$\phi$ Group differs from Normal P, $0.05>p \leq 0.001$.

into fetal cortical transplants placed into neonatal cortical areas resulted in retrograde labeling of neurons in both the ipsilateral and contralateral cortices. In our earlier analysis of thalamocortical projections, we found that tissue incubated for 6-7 weeks results in the same labeling patterns as seen with longer incubation periods. However, to insure complete labeling, we waited 8-9 weeks to analyze the distribution of DiI-filled cells. Grafts placed into the Sm host category varied in placement between SmI only or an area that overlapped both SmI and FL cortical regions. For quantitation, these grafts were treated as one type of transplant category. The corticocortical connections of the grafts corresponded in organization to the functional type of cortex previously determined by cell surface molecular characteristics (Barbe and Levitt, 1991).

\section{Normal projections of perirhinal cortex and homotopic grafts}

DiI insertion into the rostral Prh cortex of P14 nontransplanted control rats $(n=4)$ resulted in retrogradely labeled neurons in the Prh and $\mathrm{ACg}$ cortices, both limbic in function, and in two contralateral limbic regions. A diagram of a representative brain showing a typical DiI insertion site and the locations of retrogradely labeled neurons in this brain is shown in Figure 2. The mean number of labeled cells in the ipsilateral cortex is given in Table 1, while Table 3 shows that $28.9 \%$ of the projections into the rostral Prh cortex were from the $\mathrm{ACg}, \mathrm{AI}$ cortices and the Prh cortex caudal to the insertion site. Also, $71.1 \%$ of the labeled neurons in this hemisphere were located in neocortical regions, the SmI, SII, HL, and the caudalmost part of Frl. All of the cases had retrogradely labeled neurons in the ipsilateral

Table 2. Mean number of retrogradely labeled neurons present in the contralateral cortical areas analyzed following DiI labeling in the transplant or indicated area $(n=3-7$ per group)

\begin{tabular}{|c|c|c|c|c|c|c|c|c|c|c|c|c|c|c|c|c|c|}
\hline \multirow[b]{2}{*}{ Group } & \multicolumn{3}{|c|}{$\begin{array}{l}\text { Regions that project } \\
\text { into Normal } \mathbf{P}^{a} \text { only }\end{array}$} & \multicolumn{3}{|c|}{$\begin{array}{l}\text { Regions that project } \\
\text { into Normal Sm only }\end{array}$} & \multicolumn{10}{|c|}{ Graft-dependent inputs } & \multirow{2}{*}{$\begin{array}{r}\text { Total of } \\
\text { category } \\
\text { (means) }\end{array}$} \\
\hline & $\mathrm{ACg}$ & Prh & Mean $^{b}$ & SmI & FL & Mean & SII & $\mathrm{Fr}^{c}$ & $\mathrm{HL}$ & $\mathrm{Te} 1$ & $\mathrm{Te} 3$ & $\mathrm{Oc}$ & $\mathrm{PCg}$ & $\mathrm{AI}$ & GI & Mean & \\
\hline Normal $\mathbf{P}^{a}$ & 6.3 & 8.3 & $7.3^{*}$ & 0 & 0 & $0^{*}$ & 0 & 0 & 0 & 0 & 0 & 0 & 0 & 0 & 0 & 0 & 7.3 \\
\hline $\mathrm{P} \rightarrow \mathrm{P}$ & 2.7 & 6.3 & $5.4^{*}$ & 0 & 0 & $0^{*}$ & 0 & 0 & 0 & 2.7 & 0 & 0 & 0 & 0 & 0 & 0.2 & 5.6 \\
\hline $\mathrm{E} 12 \mathrm{Sm} \rightarrow \mathbf{P}$ & 4.3 & $7.7 *$ & $6^{*}$ & 0 & 0 & $0^{*}$ & 0 & 0 & 0 & 0 & 0 & 0 & 0 & 0 & 0 & 0 & 6 \\
\hline Normal Sm & 0 & $0 \phi$ & $0 \phi$ & 14 & 1 & $7.5 \phi$ & 0 & 0 & 0 & 0 & 0 & 0 & 0 & 0 & 0 & 0 & 7.5 \\
\hline $\mathrm{Sm} \rightarrow \mathrm{Sm}$ & 0 & $0 \phi$ & $0 \phi$ & 25.7 & 1 & $13.3 \phi$ & 1.3 & $\mathbf{0}$ & 3 & 0 & 0 & 0 & 0 & 0 & 0 & 0.5 & 13.8 \\
\hline $\mathrm{E} 14 \mathrm{P} \rightarrow \mathrm{Sm}$ & 5.9 & $5.6^{*}$ & $5.7^{*}$ & $34 \phi$ & 3.7 & 18.3 & $23.1 \phi^{*}$ & $35 \phi^{*}$ & 33 & 0 & 0 & 2.1 & $3.9 \phi$ & 0 & 0 & $10.8 \phi^{*}$ & 34.8 \\
\hline $\mathrm{E} 13 \mathrm{P} \rightarrow \mathrm{Sm}$ & 0 & $0 \phi$ & $0 \phi$ & 6.7 & 0 & 3.3 & 0 & 1.7 & 0 & 0 & 0 & 0 & 0 & 0 & 0 & 0.2 & 3.5 \\
\hline $\mathrm{E} 12 \mathrm{P} \rightarrow \mathrm{Sm}$ & 0 & $0 \phi$ & $0 \phi$ & 5.3 & 0.7 & 3 & 0 & 0.7 & 1 & 0 & 0 & 0 & 0 & 0 & 0 & 0.2 & 3.2 \\
\hline
\end{tabular}

Note that no regions were found that projected into both $\mathrm{P}$ and $\mathrm{Sm}$.

${ }^{a}$ DiI was inserted into rostral perirhinal cortex only in age-matched nontransplanted animals.

${ }^{b}$ Mean number of retrogradely labeled neurons in category.

' Refers to caudal frontal cortex, area 1 only, an area directly lateral to $\mathrm{ACg}$, medial to FL.

* Group differs from Normal $\mathrm{S}, 0.05>p \leq 0.001$.

$\phi$ Group differs from Normal P, $0.05>p \leq 0.001$. 
Figure 2. Diagrams showing surface reconstruction of a representative brain that received a DiI injection into rostral perirhinal cortex at P14 (large blackened area indicates spread of DiI label from injection site). Small dots represent the distribution of retrogradely labeled cells in several neocortical and limbic areas of the lateral part of the ipsilateral cortex $(A)$, the posterior cingulate cortex of the medial part of the ipsilateral cortex $(B)$, the perirhinal cortex in the lateral part of the contralateral cortex $(C)$, and the anterior cingulate cortex of the medial part of the contralateral cortex $(D)$. One dot depicts up to six labeled neurons
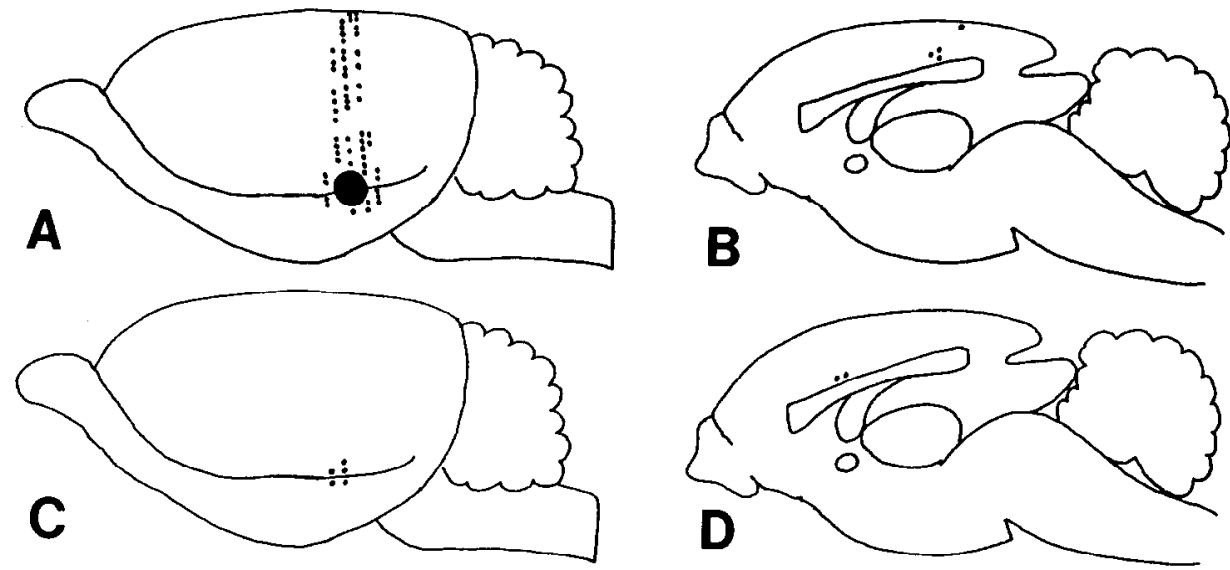

SmI and SII, one case lacked labeling in the HL, and another case lacked labeling in Frl. The retrogradely labeled neurons in the ipsilateral SmI and SII areas were arranged in disjunctive columns, with the largest numbers in layers II and V; few labeled neurons were seen in layer IV. The DiI-labeled neurons in the ipsilateral $\mathrm{ACg}$ were arranged in lamina II, V-VI, and in all of the laminae of the AI and in the Prh cortex caudal to the insertion site. Tables 2 and 4 show that the only contralateral projections into the rostral Prh cortex were from the contralateral Prh and $\mathrm{ACg}$ cortices $(100 \%)$, illustrating the lack of exuberance at this age. The heaviest concentration of labeled cells in these regions were located in laminae V-VI.

Grafts of E14 and E12 presumptive Prh cortex, placed homotopically into the neonatal rostral Prh host cortex $(n=4)$ had retrogradely labeled cells in the same areas as the Normal Prh controls as well as some additional regions. In order to facilitate defining a basic pattern of projections (e.g., limbic, nonlimbic) of each graft type, we grouped the areas containing labeled neurons into four categories (see Materials and Methods). The regions placed into these categories differ ipsilaterally from contralaterally, noted in Tables 1 and 2. The percentages of the mean number of labeled neurons in each category is compared to the sum of the category means (Tables 3 and 4). The homotopic Prh grafts received $18.6 \%$ of its ipsilateral inputs from the P-specific input category. The mean number of neurons in $\mathrm{AI}$ was significantly greater than that seen in the Normal Prh group $(0.05>$ $p \leq 0.001$ ), but the mean of the whole P-specific category did not differ significantly from the normal $\mathrm{P}$ control group
( $p>0.05$ ). The majority of the retrogradely labeled neurons, $58.8 \%$, were in the P and Sm category (Frl, HL, SmI, and SII; Table 3). Only two of the brains in this latter group had inputs from the ipsilateral HL and rostral Frl areas. In addition to inputs from the above categories, $9.8 \%$ of the retrogradely labeled neurons from the homotopic Prh grafts were mapped to the auditory cortices of two of the brains (the Sm-specific category), suggesting that the $\mathrm{Te} 1$ and $\mathrm{Te} 3$ cortices were at least partially included in the dissections of the perirhinal slabs used for grafting. There also were DiI-labeled neurons in the ipsilateral $\mathrm{PCg}$ in two of these brains and GI in three of the brains, these two cortical regions being part of the graft-dependent category (12.8\%). Guildin and Markowitsch (1983) showed that PCg does project into certain parts of the perirhinal cortex, suggesting that some of our fetal Prh slabs contained these areas. Despite these minor differences, the overall variance of the mean number of neurons in all of the areal locations ipsilaterally was not significantly different between the homotopic Prh group and the Normal P control group ( $p \geq 0.24$ ).

The results are also clear contralaterally in the homotopic Prh grafted group compared to the Normal Prh animals (Tables 2, 4). Most of the retrogradely labeled cells $(96.4 \%)$ in the contralateral cortex were located in the $\mathrm{ACg}$ and Prh cortices (the P-specific category). The only retrogradely labeled neurons in the contralateral graft-dependent category were located within one of the brains in the Tel region. This brain had eight labeled cells in the contralateral $\mathrm{Tel}$ cortex, 2 in the contralateral $\mathrm{ACg}$, and 7 in the contralateral Prh cortex, strongly implying that this

Table 3. Percentage of mean number of retrogradely labeled neurons present in each category of ipsilateral cortical areas compared to total of category means

$\begin{array}{lllll} & \begin{array}{l}\text { Regions that project } \\ \text { into Normal P only } \\ \text { (ACg, A1, Prh) }\end{array} & \begin{array}{l}\text { Regions that project } \\ \text { into both P and Sm } \\ \text { (Fr1, }{ }^{2} \text { HL, Sml, SII) }\end{array} & \begin{array}{l}\text { Regions that project } \\ \text { into Normal Sm } \\ \text { only }\end{array} & \begin{array}{l}\text { Graft-dependent } \\ \text { inputs }\end{array} \\ \text { (Troup } & 28.9 & 71.1 & 0 & 0 \\ \text { Normal P } & 18.6 & 58.8 & 9.8 & 12.8 \\ \mathrm{P} \rightarrow \mathrm{P} & 43.8 & 33.9 & 16.1 & 6.1 \\ \mathrm{E} 12 \mathrm{Sm} \rightarrow \mathrm{P} & 0.17 & 86.7 & 13.0 & 0 \\ \text { Normal S } & 7.2 & 83.0 & 9.8 & 0 \\ \mathrm{Sm} \rightarrow \mathrm{Sm} & 12 & 59.9 & 19.0 & 8.6 \\ \mathrm{E} 14 \mathrm{P} \rightarrow \mathrm{Sm} & 1 & 2.8 & 0 \\ \text { E13 P } \rightarrow \mathrm{Sm} & 96.2 & 36.1 & 0 \\ \mathrm{E} 12 \mathrm{P} \rightarrow \mathrm{Sm} & 0.8 & 63.1 & \end{array}$

${ }^{a}$ Refers to caudal frontal cortex, area 1 only, an area directly lateral to $\mathrm{ACg}$, medial to $\mathrm{FL}$. 
Table 4. Percentage of mean number of retrogradely labeled neurons present in each category of contralateral cortical areas compared to total of category means

\begin{tabular}{lccc} 
& $\begin{array}{l}\text { Regions that project } \\
\text { into Normal P only } \\
\text { (ACg, Prh) }\end{array}$ & $\begin{array}{l}\text { Regions that project } \\
\text { into Normal Sm only } \\
\text { (FL, SmI) }\end{array}$ & $\begin{array}{l}\text { Graft-dependent inputs } \\
\text { (SII, Fr1, }{ }^{,} \text {HL, Te1, Te3, } \\
\text { OC, PCg, AI, GI) }\end{array}$ \\
\hline Normal P & 100 & 0 & 0 \\
P into P & 96.3 & 0 & 3.9 \\
E12 Sm $\rightarrow$ P & 100 & 0 & 0 \\
Normal S & 0 & 100 & 0 \\
Sm $\rightarrow$ Sm & 0 & 96.4 & 3.5 \\
E14 P $\rightarrow$ Sm & 16.4 & 52.6 & 28.6 \\
E13 P $\rightarrow$ Sm & 0 & 94.3 & 5.7 \\
E12 P S S & 0 & 93.8 & 6.2 \\
\hline
\end{tabular}

Note that no regions were found that project into both $\mathrm{P}$ and $\mathrm{Sm}$.

"Refers to caudal frontal cortex, area 1 only, an area directly lateral to $\mathrm{ACg}$, medial to FL.

one graft included the adjacent Tel region as well as the rostral Prh cortex

These labeling patterns are comparable to other studies showing that the rodent rostral perirhinal cortex receives ipsilateral connections from anterior and posterior cingulate (the latter depending on whether rostral or caudal perirhinal areas were labeled), caudal perirhinal, agranular insular and many neocortical cortices such as SII, and commissural connections from the contralateral rostral perirhinal and cingulate cortices (Deacon et al., 1983; Guildin and Markowitsch, 1983).

\section{Normal projections of sensorimotor cortex and homotopic grafts}

DiI was placed directly into the SmI area of three normal brains from aged P14 rats, and into both the FL and SmI of two normal brains. The labeling patterns were assessed as 1 group. The grafts were placed similarly, and thus were also assessed as 1 group (Tables 1-4). A drawing with the distribution of labeled cells in a representative brain is shown in Figure 3 . The majority $(86.7 \%)$ of the labeled neurons in the ipsilateral cortex were located in the category of regions that project into both the Normal Prh and Sm cortices; this category contains caudal Fr1, HL, SmI, and SII (Tables 1, 3). The ipsilaterally labeled neurons in this category were located in laminae II-III and V-VI in a columnar pattern. The ipsilateral FL was not included in the quantification because the extreme brightness of $\mathrm{DiI}$ in this region prevented the counting of cells in several of the brains. Labeled neurons in the SmI cortex that extended caudal from the insertion site were able to be counted. The cortical regions that were labeled exclusively in the Normal Sm brains (Te1, Te3, and Oc) contained $13 \%$ of the labeled cells. There was also a very small number of labeled neurons $(0.17 \%)$ in the ipsilateral $\mathrm{ACg}$ area of the P-specific category. The number of labeled neurons in this latter category was significantly less than the Normal Prh control brains ( $p \leq 0.001$ ). Contralaterally, $100 \%$ of the labeled neurons were located in the SmI and FL cortices, with the majority in SmI. The location of even a few retrogradely labeled neurons in the contralateral FL area (Table 2) suggests that either the location of the DiI insertion site and/or the spread of DiI from the insertion site included an area in some of the brains that overlapped at least partially with the adjacent FL cortex.

Homotopic sensorimotor grafts into $\operatorname{SmI}(n=3)$ gave labeling results that were similar to control Sm brains (Tables $1-4 ; p>$ 0.5 ). The vast majority of the ipsilateral cells, $83 \%$, were located in the $\mathbf{P}$ and Sm category. The ipsilateral Sm-specific category contained $9.8 \%$ of the DiI-labeled neurons, with the majority of the labeled cells mapping to the Oc cortex. There were also inputs in one of the brains from the ipsilateral Prh cortex. The number of labeled neurons in the P-specific category was significantly lower in this homotopic Sm graft group than the Normal Prh control animals ( $p \leq 0.04$ ) or the homotopic Prh graft group ( $p \leq 0.03$ ). Contralaterally (Tables 2,4 ), 96.4\% of the inputs into the homotopic Sm grafts were from the Sm-specific category, primarily in the homotopic SmI region. There were
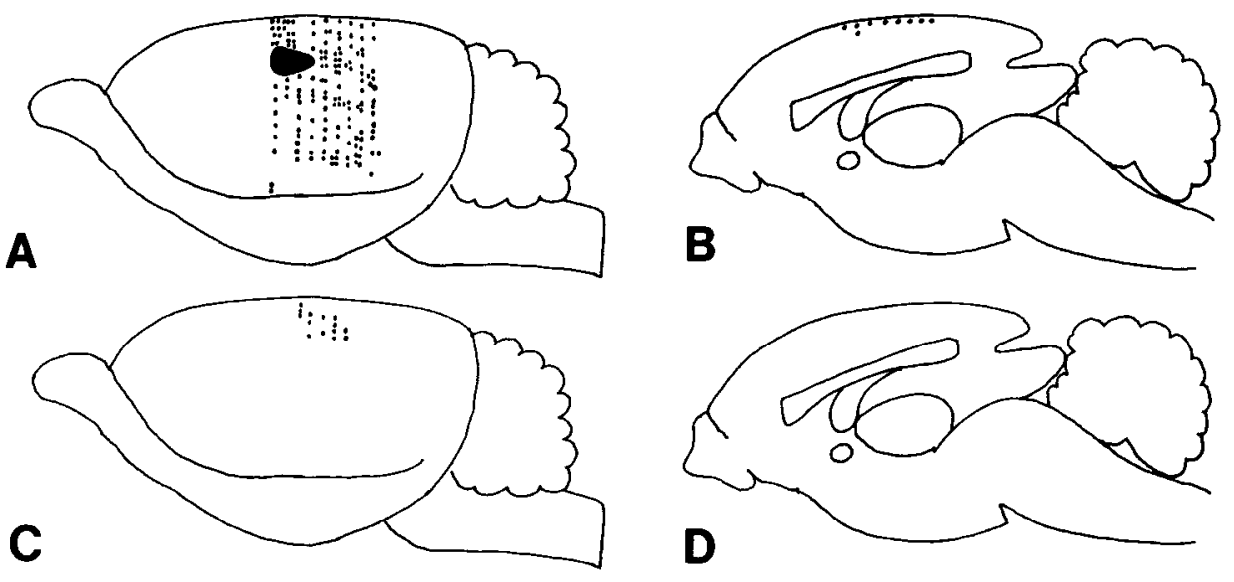

Figure 3. Diagrams showing surface reconstruction of a representative brain that received a Dil injection (large black area) into the primary sensorimotor cortex. Ipsilaterally, retrogradely labeled cells are present in patchy patterns in most of the neocortical areas mapped $(A, B)$, but are present in the contralateral cortex only in the cortical area homotopic to the injection site (C). Note the lack of retrogradely labeled cells in this brain's cingulate cortices, both ipsilaterally and contralaterally, $B$ and $D$, respectively. Symbols are as in Figure 2. 

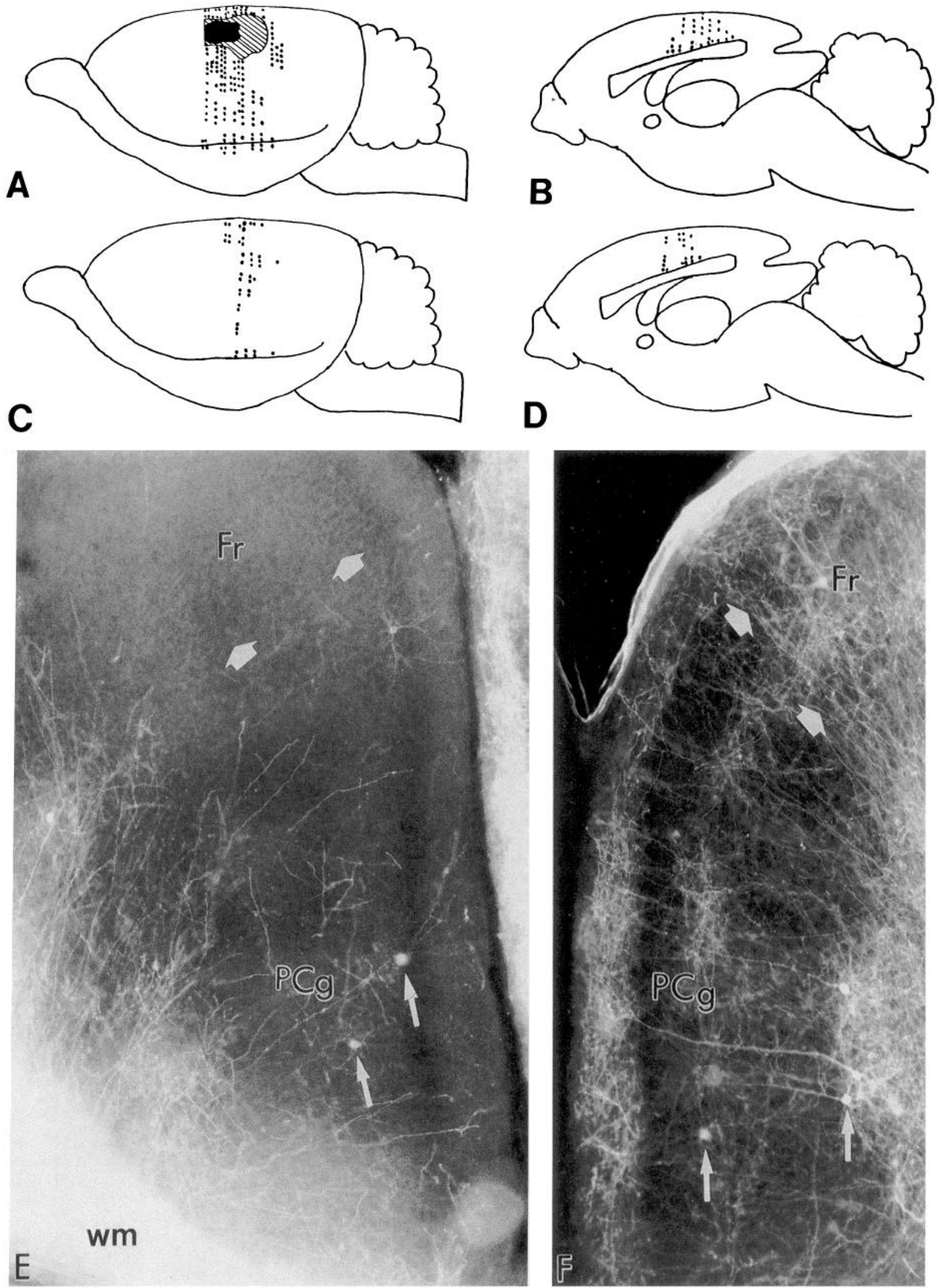

Figure 4. Diagrams showing surface reconstruction of a representative P14 brain that received a DiI injection (large black area) into a transplant (cross-hatched area and including blackened area) of a piece of E14 perirhinal cortex placed into the primary sensorimotor area of a neonate. DiIlabeled cells are present ipsilaterally in several neocortical areas such as SmI, SII, and auditory, as well as the associated insular cortices such as AI, GI and perirhinal $(A)$, and in the cingulate and caudal frontal area 1 cortices on the medial surface of the ipsilateral hemisphere $(B)$. In the contralateral side $(C, D)$, retrogradely labeled cells are present in both several sensory-motor associated cortices as well as limbic areas such as the perirhinal and cingulate cortices. This distribution of labeled cells indicates a hybrid limbic and sensorimotor input pattern for this transplant group. 

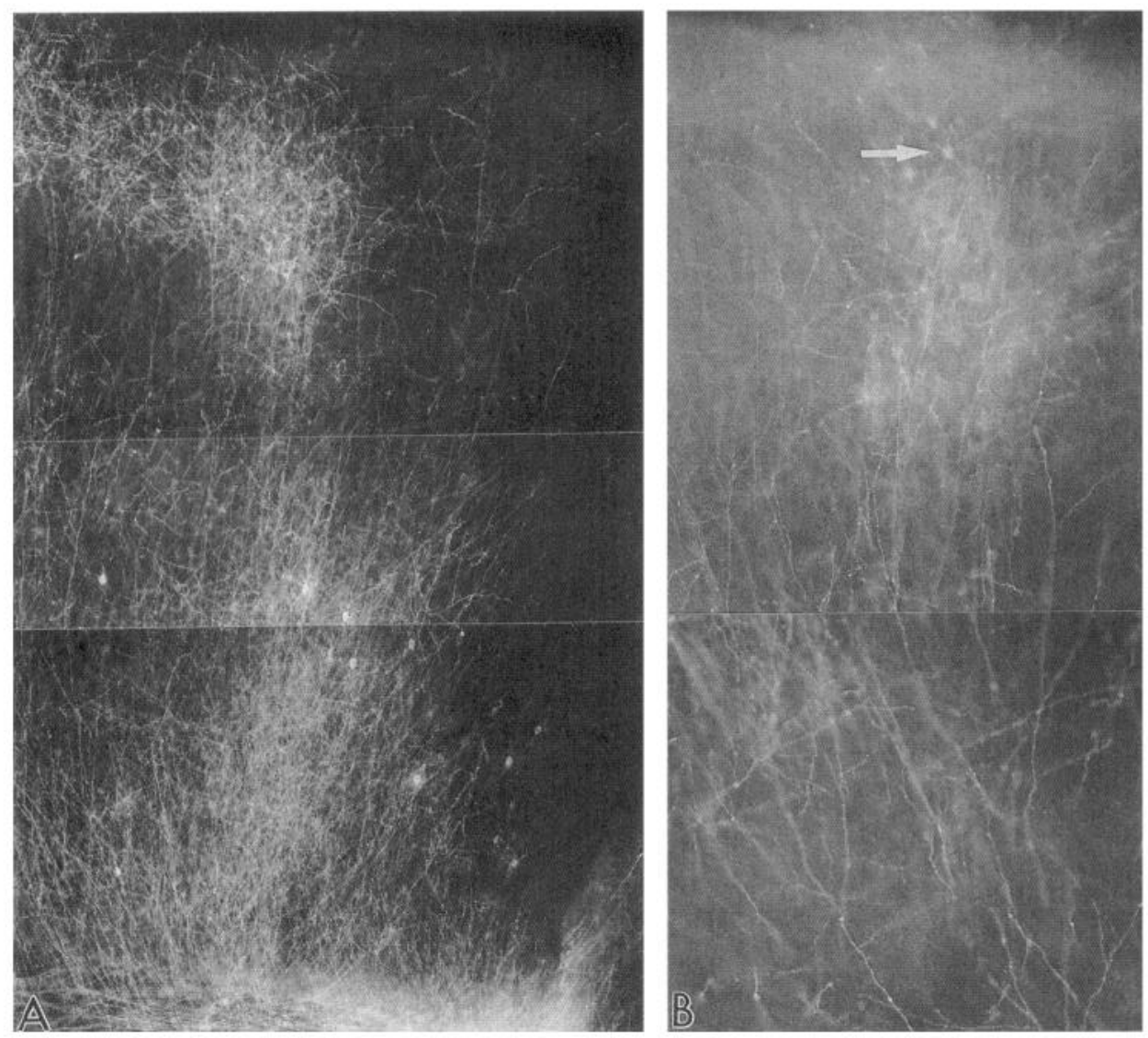

Figure 5. Photomicrographs from a brain that received an E14 perirhinal graft into the sensorimotor cortex of a neonate that was labeled with DiI 2 weeks after transplantation. $A$, Micrograph of the contralateral SmI showing retrogradely labeled cells in lamina III, $\mathrm{V}$, and VI and labeled axons in laminae I, III, V, and VI. Note the columnar arrangement of labeled axons and cells, with few located in the cortical area in the right part of the field. $B$, Micrograph of the contralateral perirhinal cortex showing retrogradely labeled cells in laminae II and III (arrow).

also four labeled cells present in the contralateral SII cortex of one of the three brains analyzed, and nine labeled neurons in the FL region of another brain. There were no significant differences between the overall number and areal location of contralaterally labeled neurons in the homotopic Sm grafts compared to the Normal Sm control group ( $p \geq 0.58$ ). As Table 2 shows, however, there were significant differences in the types of contralateral inputs into these grafts when compared to the Normal Prh control animals in the P-specific and Sm-specific categories, the former category being significantly less and the latter category being significantly more than labeled neurons in these categories in the Normal Prh labeled brains $(p \leq 0.001$ each).

The labeling patterns in both Normal Sm and the homotopic Sm grafted animals are comparable to previous degeneration and retrogradely transported horseradish peroxidase studies, reporting that the sensorimotor area of the adult rat receives commissural connections from the contralateral sensorimotor cortices, and ipsilateral connections from a wide variety of neocortical areas (Wise and Jones, 1976, 1978; Akers and Killackey, 1978; Vogt and Miller, 1981; Donoghue and Wise, 1982).

\section{Heterotopic E14 perirhinal grafts placed into neonatal sensorimotor cortices}

The E14 perirhinal transplants that were included in the final analysis were placed into three closely related locations: (1) three grafts located exclusively in the SmI region, (2) one graft located exclusively in the FL region, and (3) three grafts that overlapped into both SmI and FL cortices. The results of all seven are tallied as one group in Tables 1 and 3 and will be discussed following a summary of the results of inputs into the separate graft placement types. In type A, DiI labeling resulted in retrogradely labeled cells in several sensorimotor and limbic areas both ipsilaterally and contralaterally. Figure $4 A-D$ is a representative diagram of type A's placement site and labeling pattern. The ipsilateral inputs into these grafts were as follows: $60 \%$ were located in the P and S input category, $7.3 \%$ in the P-specific category, $18 \%$ in the Sm-specific category, and $15 \%$ in the graft-dependent category. The contralateral inputs into the type A grafts were $36.6 \%$ in the P-specific category, $33 \%$ in the Smspecific category (only one cell was located in the FL region of one of these three brains, the remainder being located in SmI) and $28.5 \%$ in the graft-dependent category. Retrogradely labeled

$E$ and $F$, Photomicrographs from a E14 Prh into SmI representative brain. $E$, Micrograph of the contralateral posterior cingulate area showing retrogradely labeled cells in lamina I and III (long arrows, Short, wide arrows indicate boundary between posterior cingulate cortex and caudal motor cortex (Fr1). F, Ipsilateral posterior cingulate gyrus of same brain showing retrogradely labeled cells in lamina III and V (long arrows) and labeled axons branching in laminae I, III, V, and VI. Short, wide arrows indicate boundary between posterior cingulate and caudal Frl cortex. Symbols are as in Figure 2. 
Figure 6. Representative diagrams $(A-D)$ of a brain that received an E13 perirhinal transplant into the sensorimotor cortex of a neonate (transplant site indicated by cross-hatching). DiI was inserted into the transplant on P13 (black area in transplant site). Ipsilateral lateral $(A)$ and medial $(B)$ surfaces of the hemispheres show retrogradely labeled neurons in SmI and II and auditory cortices. $(C)$ The contralateral hemisphere has retrogradely labeled cells in the homotopic SmI area only. (D) No labeled cells is evident on the contralateral medial surface. Micrographs $(E$ and $F)$ from another representative brain show retrogradely labeled cells in the contralateral $\mathrm{Sm}$ cortex $(E)$. The white matter tracts are located in the lower left-hand edge of the micrograph. Note that in the contralateral SmI cortex that the retrogradely labeled cells and fibers are arranged into patchy columns. $F$, No retrogradely labeled cells are present in the contralateral posterior cingulate cortex $(P C g)$. wm, white matter. Symbols are as in Figure 2.
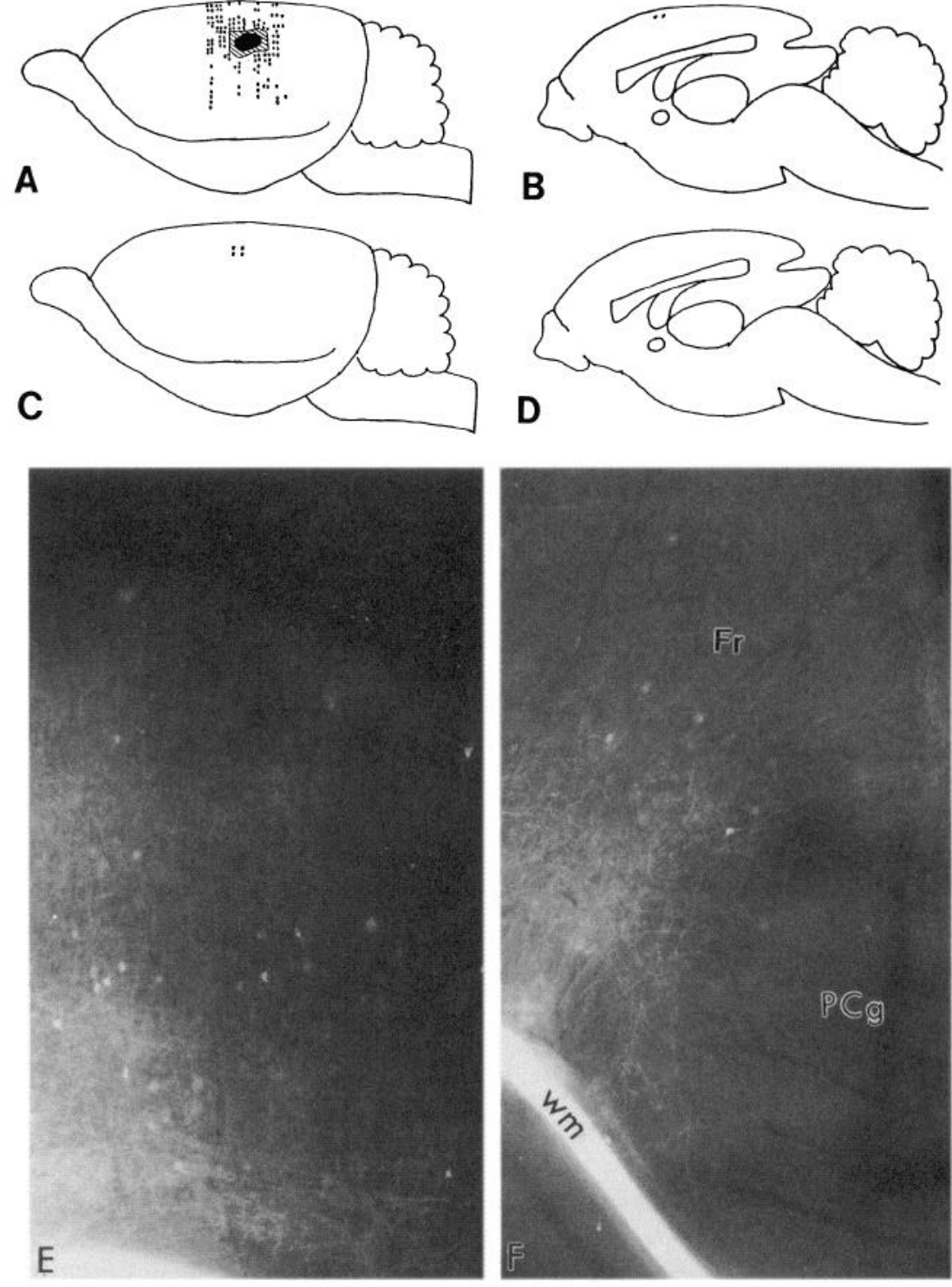

cells were located in laminae I-III in the contralateral PCg cortex (Fig. $4 E$ ) and in laminae 1, III and V of the ipsilateral $\mathrm{PCg}$ cortex (Fig. $4 F$ ). There may have been labeled neurons in lower layers of the contralateral posterior cingulate cortex was well, but the DiI labeling of crossing commissural fibers as too bright to distinguish labeled neurons in this area. Dil-labeled cells in the contralateral SmI of these grafts were located in lamina III, V-VI (Fig. 5A). The labeled cells in the contralateral Prh cortex were scattered throughout the laminae; Figure $5 B$ shows labeled cells in the upper laminae of this cortex.

In type B of E14 P into Sm graft placement, the retrogradely labeled cells on the ipsilateral side are present primarily in SmI, SII, HL, FL, Te1, with fewer neurons located in cingulate and insular cortices. Contralateral inputs were from both cingulate regions, the Prh, SmI, FL, HL, and Frl cortices. In type C of graft placement, the ipsilateral inputs were as follows: $53.6 \%$ were located in the P and Sm input category, $13 \%$ in the P-specific category (only one of the brains had labeling in $\mathrm{ACg}, 5$ cells out of 60 total in that hemisphere), $16.5 \%$ in the Sm-specific category and $17 \%$ in the graft-dependent category. The contralateral inputs into these grafts were $8.6 \%$ in the P-specific category, $66.8 \%$ in the Sm-specific category and $24 \%$ in the graft-dependent category, the labeling within this latter category being located in the regions SII, HL, Frl, and PCg.

When one considers all seven E14 Prh into Sm brains together (Tables 1,3), approximately $60 \%$ of the ipsilateral DiI-labeled neurons are located in the $\mathrm{P}$ and Sm category, $12 \%$ in the P-specific category, $19 \%$ in the Sm-specific category, and $8.6 \%$ in the remaining graft-dependent input category. Table 1 shows that the number of labeled neurons in the P-specific input category was significantly higher than the same category in the Normal Sm control group, but are very similar to the mean number of labeled neurons in these areas of the Normal Prh animals. The mean number of labeled neurons is high in the three other input categories, significantly higher than the Normal Prh control group in the P and Sm input category, and significantly higher than both control groups in both the Sm-specific and the graftdependent categories. Overall, the mean number of the ipsilaterally labeled neurons in the E14 P into Sm grafted animals was higher than the Normal Prh control group $(p \leq 0.01)$ and the Normal Sm control group ( $p \leq 0.02$ ). The higher number of inputs into these E14 grafts suggests that an exuberant num- 

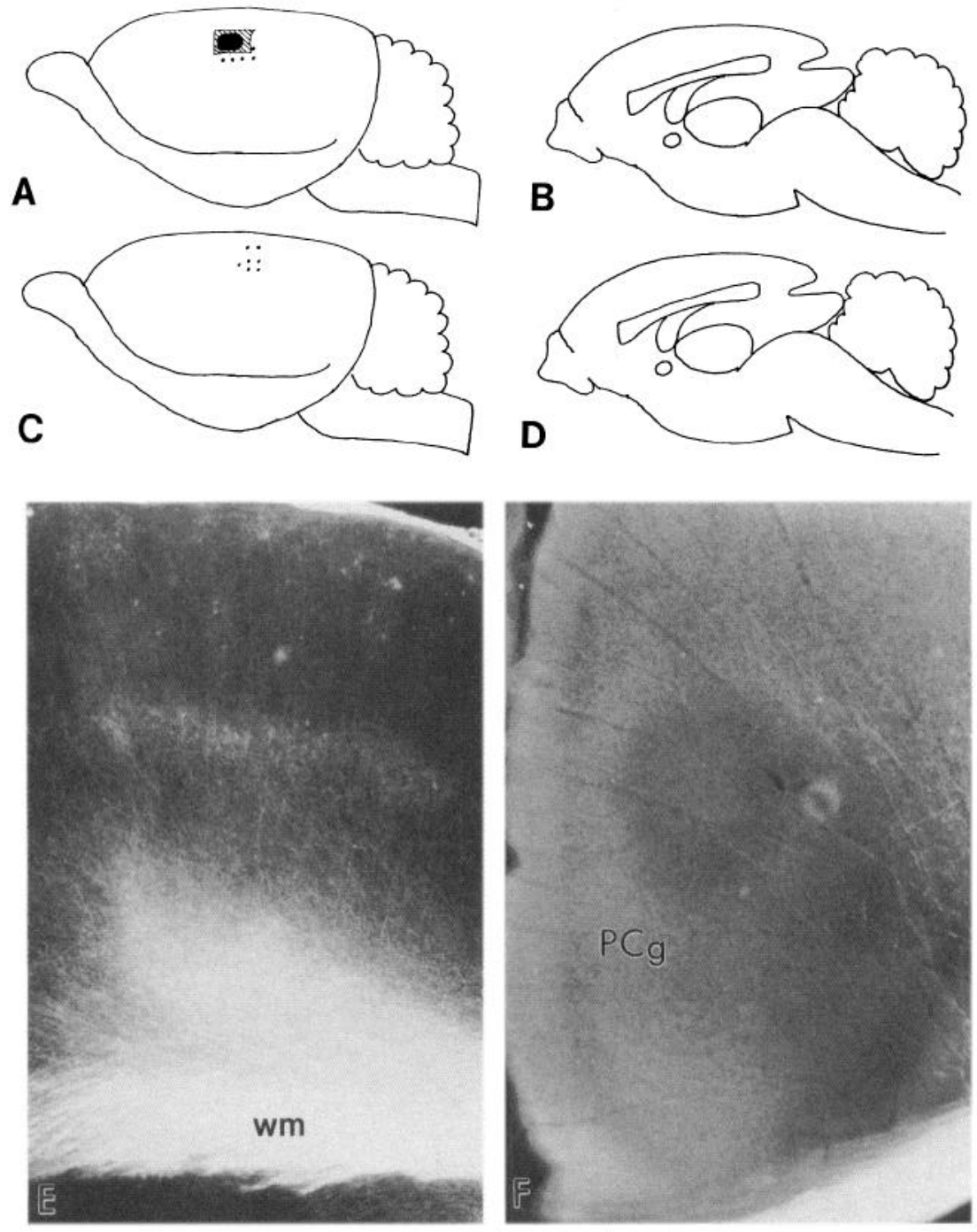

Figure 7. Representative diagrams $(A-D)$ of a brain that received a transplant of E12 presumptive perirhinal cortical wall into the sensorimotor cortex at P0. DiI was inserted on P13. Ipsilateral lateral $(A)$ and medial $(B)$ cortical hemispheres show retrogradely labeled cells in SmI area around the transplant site only. Contralateral lateral $(C)$ and medial $(D)$ cortices have labeling only in the homotopic SmI area. Representative micrographs $(E$, $F$ ) of another brain from the same group show retrogradely labeled cells in the contralateral SmI cortex $(E)$ in laminae I-III. No retrogradely labeled cells are present in the contralateral posterior cingulate cortex $(F)$. Symbols are as in Figure 2. ber of inputs are being maintained, but which are lost in the E13 and E12 P into $\mathrm{Sm}$ grafts (see Tables 1,3). The presence of labeled cells in the PCg in four of the brains suggests that the dissections of these brains may have included caudal Prh cortex in addition to the rostral Prh cortex, since the caudal perirhinal cortex has been shown to receive inputs from that region (Guildin and Markowitsch, 1983). However, these inputs were not in the E13/E12 P into Sm grafts from the PCg cortex (presumably dissected in a similar manner), suggesting perhaps a maintenance of exuberant inputs ipsilaterally into the E14 P into Sm grafts.

Contralaterally, the results are clearer. The E14 P into Sm grafts receive a hybrid mixture of commissural inputs. Tables 2 and 4 show that the E14 P into Sm grafts received inputs from both the P-specific and the Sm-specific input categories, 16.4\% and $52.6 \%$, respectively. In the Normal Prh only input category, five of the seven grafts received projections from the contralateral $\mathrm{ACg}$ cortex while six of the brains had input from the contralateral Prh cortex. The mean number of labeled neurons in this category was significantly higher than the Normal Sm control animals. The number of labeled neurons in the graft-dependent category of inputs also was significantly higher than both control groups, possibly due to the dissection technique, placement of the graft, or exuberance again. The sensorimotor and limbic type inputs contralaterally in this graft group could also be due to a maintenance of some of the developmentally normal exuberant cortical collaterals that have already died back in the control animals (Wise and Jones, 1976, 1978; Ivy et al., 1979; Valentino and Jones, 1982), resulting in a hybrid cortex in terms of connectivity.

\section{Heterotopic E13 perirhinal grafts into neonatal sensorimotor cortex}

While the E14 grafts exhibited a mixture of input patterns, the inputs to the E13 grafts were more straightforward, appearing more like normal $\mathrm{Sm}$. There were retrogradely labeled neurons primarily in the SmI cortex both ipsilaterally and contralaterally. A drawing with the distribution of labeled cells in a representative brain is shown in Figure $6 A-D$, and the results are summarized in Tables 1-4. DiI labeling of the graft site resulted in many ipsilaterally located, retrogradely labeled neurons $(96.2 \%)$ in the $\mathrm{P}$ and $\mathrm{S}$ category of inputs. There were also four cells labeled in one of the brains in the ipsilateral Prh cortex (the $\mathrm{P}$-specific input category). The number of labeled neurons in this latter category was significantly lower than the Normal Prh control animals ( $p \leq 0.001$ ), as well as the E14 P into Sm and $\mathrm{E} 12 \mathrm{Sm}$ into $\mathrm{P}$ groups. The auditory areas in the $\mathrm{Sm}$-specific category also projected into these grafts; however, the mean 

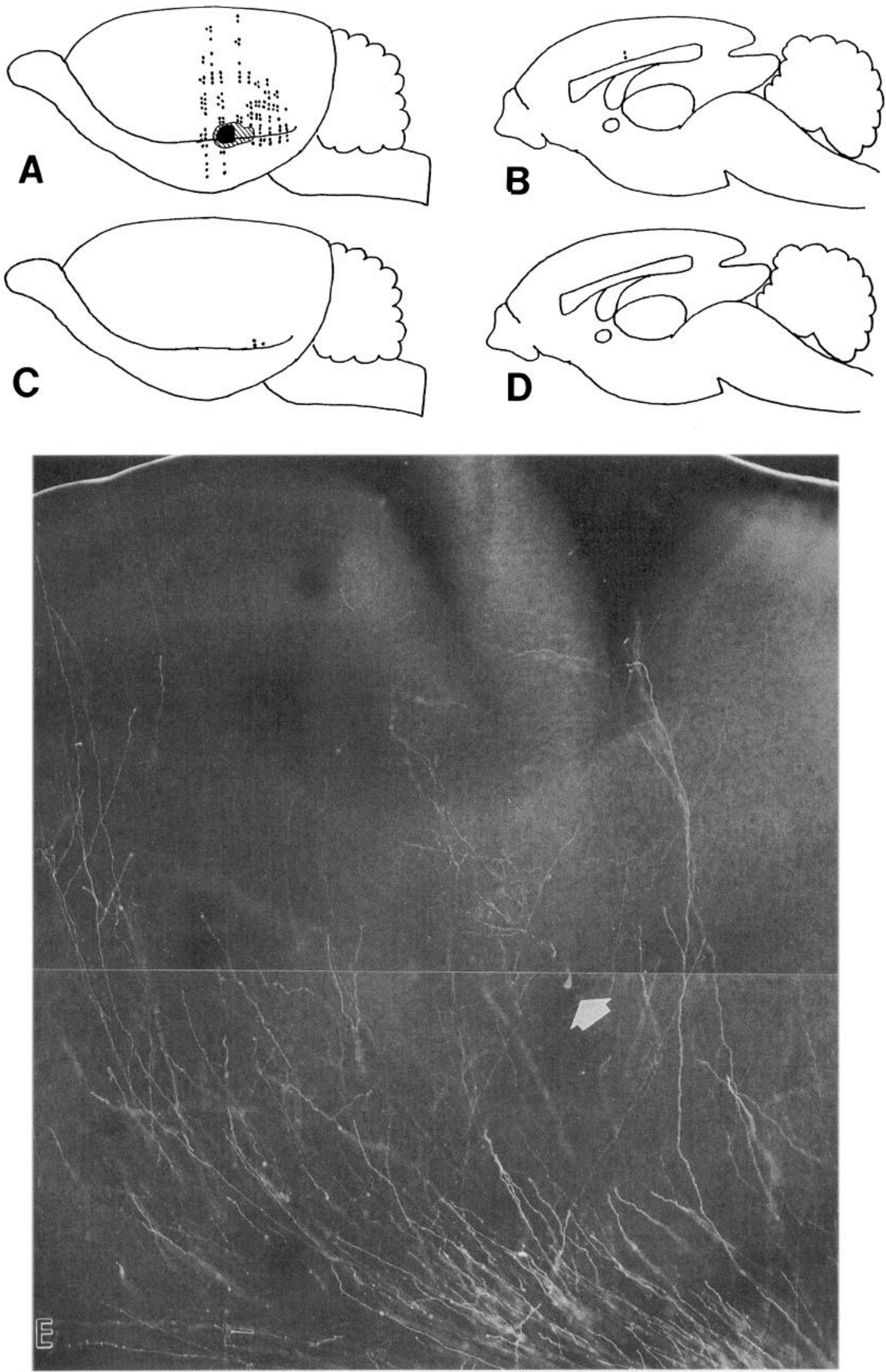

Figure 8. Representative diagrams $(A-D)$ of a brain that received a transplant of E12 presumptive sensorimotor cortical wall into the perirhinal cortex at age P0. DiI was inserted on P13. Retrogradely labeled cells are present in the ipsilateral lateral hemisphere $(A)$ and are located in both neocortical areas (SI, SII, Tel, and Te3) and mesocortical and archicortex cortical areas (piriform cortex and perirhinal cortex caudal to the rostrally placed graft). $B$, Medial view shows retrogradely labeled cells in the anterior cingulate cortex. $C$, The contralateral hemisphere shows retrogradely labeled cells in the homotopic perirhinal cortex only. $D$, No labeled cells are present in the medial part of the contralateral hemisphere. $E$, Micrograph 
number of laheled neurons in this category was not significantly different than the Normal Sm controls. The neurons in the ipsilateral neocortical areas were present in lamina II-III, and V, a normal distribution pattern for ipsilaterally projecting corticocortical neurons. The retrogradely labeled cells present in the ipsilateral Prh cortex were located throughout all the laminae of that area, again a normal distribution pattern compared to the controls. Retrogradely labeled cells were not present in the ipsilateral $\mathrm{ACg}, \mathrm{PCg}$ or Oc cortices.

Again, in contrast to the E14 grafts heterotopic grafts that receive inputs from both contralateral sensorimotor and limbic regions, the E13 P into Sm grafts received $94.3 \%$ of their contralateral inputs from the Sml cortex (lables 2, 4), one of the regions in the Sm-specific category. As in the control cases, the contralatcrally located, retrogradely labeled ncurons in the SmI cortex were arranged in columns and patches and were situated mostly in laminae II-III and V-VI of the host cortex (Fig. 6E). One of the brains also had five labeled neurons in the contralateral graft-dependent region Fr1 (6.2\% of all the inputs). There were no contralateral inputs from the $\mathrm{P}$-specific category (Tables 2, 4; Fig. $6 F$ ), as there were in the Normal Prh controls and the E14 P into Sm graft group.

\section{Heterotopic E12 perirhinal grafts into neonatal sensorimotor cortex}

This graft category, like at E13, resulted in projection patterns most like Normal Sm. The E12 P into Sm grafts were placed primarily in the SmI cortex ( $n=3$ analyzed). A representative diagram (Fig. 7) shows the graft site and the location of retrogradely labeled neurons. The results are summarized in Tables $1-4$. Most of the ipsilatcral affercnts $(63.1 \%)$ arose from the $P$ and $\mathrm{Sm}$ input category. The majority of these neurons were located in the SmI area caudal to the transplant, although labeled neurons were also located in SII, HL, and Frl in most of the brains. An additional $36 \%$ of the inputs into this graft type were from the Sm-specific category. In the ipsilateral P-specific category, there were two or three labeled neurons/brain that mapped to the $\mathrm{ACg}$ cortex. The number of labeled neurons in this latter category of ipsilateral inputs into the grafts were significantly lower than those to Normal Prh control animals ( $p<$ 0.004), as well as the E14 P into Sm and E12 Sm into P graft groups. As expected for grafts with Sm-like features, there was a significantly higher number of ipsilateral inputs from the Smspecific category of inputs when compared to the Normal Prh control group, but no significant differences were found overall between this graft group ipsilaterally when compared to the Normal Sm control animals ( $p \geq 0.73$ ).

The E12 heterotopically located perirhinal grafts received contralateral afferents mostly from homotopic SmI cortical region (Fig. 7C,E) and FL (Fig. 7C), with a few retrogradely labeled neurons mapping to the $\mathrm{HL}$ and motor areas Fr1 (Table 2 ) in some of the brains. No labeled cells were present contralaterally in the limbic $\mathrm{PCg}$ (Table 2, Fig. $7 F$ ) or Prh cortices. The laminar arrangement of all the contralaterally labeled cells in SmI was normal, located in layers II-III, and V-VI (Fig. 7E). As seen ipsilaterally, there were no significant differences between this graft group from the Normal Sm control animals in any of the categories or nverall $(p>0.94)$. The number of labeled neurons in the Prh-specific category of inputs was significantly lower than the Normal Prh control animals ( $p \leq$ 0.001 ), as well as the E14 P into Sm, E12 Sm into P, and homotopic P graft groups.

\section{Heterotopic EI2 sensorimotor grafts into neonatal perirhinal cortex}

The E12 sensorimotor into rostral perirhinal grafts $(n=3$ analyzed) received many inputs similar to the control rostral Prh cortex (Tables 1-4). A representative brain is shown in Figure $8 A-D$. These grafts received many ipsilateral inputs from both the P-specific $(43.8 \%)$ and the $\mathrm{P}$ and $\mathrm{Sm}(33.9 \%)$ categories. The number of ipsilateral inputs in these two categories to this graft type were significantly greater than the Normal Sm control animals, $p \leq 0.02$ for the P-specific category, and $p \leq 0.05$ for the $\mathrm{P}$ and $\mathrm{Sm}$ category. In addition to the inputs from the above categories, $16.1 \%$ of the DiI-labeled neurons are located in the auditory cortices of the Sm-specific category and $6.1 \%$ in the GI cortex of the graft-dependent category. The presence of inputs in the auditory cortex could be due to the dissection technique of the E12 presumptive Sm cortex. The input from GI cortex is not inappropriate, as it is part of the same insular association cortex that includes the perirhinal cortex. There were no significant differences in either the categories or overall in the number of neurons or areal locations in this graft type when compared to the Normal Prh control animals (Table 1).

Retrogradely labeled neurons are located contralaterally in only the limbic Prh and $\mathrm{ACg}$ cortices of the P-specific input category following placement of E12 sensorimotor grafts into host perirhinal cortex (Tables 2, 4). Figure $8 E$ shows a DiIlabeled cell located in the contralateral perirhinal cortex as well as DiI-labeled axons. Contralaterally, this graft type has very different inputs from the Normal Sm controls in both the P-specific and the Sm-specific categories (Tables 2, 4). Also, the number of neurons in the P-specific category were significantly higher in the E12 Sm into P graft group than the E13 P into Sm, the E12 P into Sm, and the homotopic Sm graft groups.

\section{Summary of results}

The ipsilateral and contralateral inputs of the heterotopic transplants of E12 and E13 grafts are very characteristic of their new host locale, while those inputs of the E14 grafts exhibited hybrid features, both of their original and new environment. Contralaterally, the input patterns are very similar in the P-specific category when comparing the Normal Prh, Homotopic Prh, and E12 Sm into P groups. The E14 P into Sm graft group also has labeled neurons in this category. The similarity in the Sm-specific input category is striking between the Normal Sm, homotopic $\mathrm{Sm}$, and the three heterotopic perirhinal graft groups. The only graft group that has commissural inputs from both of these categories of regions is the E14 P into Sm, suggesting that it has a hybrid mixture of sensorimotor and limbic functional inputs. This graft group also has significantly more ipsilateral connections with the Prh, ACg, and AI regions than the Normal Sm, homotopic Sm, and E13/E12 heterotopic Prh graft groups,

$\leftarrow$

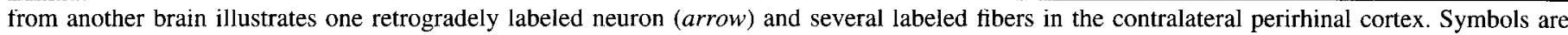
as in Figure 2. 
in addition to a large number of inputs from the sensorimotortype cortices ipsilaterally.

\section{Discussion}

In our studies of cerebral cortical grafts, we have presented results suggesting that there is an early, restricted period of fetal development in which cortical cells can exhibit marked plasticity in the expression of specific phenotypic traits (Barbe and Levitt 1991, 1992b; Levitt et al., 1993). Certain features of these cells may be altered by extrinsic factors in the new host milieu through E13, after which (E14) the donor transplanted tissue begins to express certain features characteristic of its cortical origin in addition to its new host environment. This conclusion is based on the analysis of three phenotypes: (1) the expression of the limbic cortical marker protein LAMP (Levitt, 1984; Horton and Levitt, 1988; Barbe and Levitt, 1991), (2) the organization of thalamocortical projections (Barbe and Levitt, 1992b), and (3) in the present study, corticocortical projections.

\section{Developmental timing and commitment to corticocortical phenotypes}

In the present study, we show that the local cues of the host newborn rat cortex are capable of mediating the differentiation of precursor cells in the E12 cortical grafts. The heterotopic transplants of E12 tissue exhibit many afferent corticocortical connections that reflect those typical of the new host locale (although there still appears to be some nonspecific inputs ipsilaterally at this time point of study of the grafts). Because the cerebral wall at E12 contains almost exclusively progenitor cells (Hicks and D'Amato, 1963; Bayer and Altman, 1991), the data suggest that the precursors are cxposed to cucs in the new arca that are able to affect a sequence of differentiative events, including the final commissural projection patterns of the daughter cells (and at least partially the ipsilateral projection patterns). Heterotopic transplantation of E14 tissue produces grafts exhibiting mixed, or hybrid corticocortical connections. The hybrid phenotype is abnormal, reflecting features of both the donor origin and the new host locale. This complex result was also obtained in our analysis of the molecular phenotype and thalamocortical projection patterns of similar transplants (Barbe and Levitt, 1991, 1992b), and in the analysis of efferents of occipital grafts placed into host Sm regions (Ebrahimi-Gaillard et al., 1994). We believe the formation of a mixed phenotype in our studies, normally not seen, is probably due to the extended period of time, E13-17, over which neurons are generated in the rostral and lateral cortices (Hicks and D'Amato, 1968; Altman and Baycr, 1990). Thus, at E14, the lateral cerebral wall contains both precursor cells and postmitotic neurons in the process of migration to the cortical plate. In contrast, E17 cortical neurons exhibit a more homogenous molecular phenotype after transplantation (Barbe and Levitt, 1991). Our previous and present findings support our hypothesis that the specification of the cerebral cortex is due to an interaction of both genetic and external cues that act upon cells in a time-dependent fashion (Levitt et al., 1993), restricting their commitment to express specific phenotypes over an extended period of development. While the transplant data shows that E12 precursors clearly have not irreversibly committed to a specific phenotype, and thus are amenable to regulation by extrinsic cues, cell culture results (Ferri and Levitt, 1993) suggest that there is some fating of the progenitors to express a limbic phenotype. These experiments reveal that precursors from presumptive perirhinal and sensori- motor cortices, when grown in culture under identical defined conditions, will differentiate into LAMP-positive and negative neurons, respectively. Our and other recent analyses of the connectivity and molecular features of cortical grafts (Cohen-Tannoudji et al., 1994; Ebrahimi-Gaillard et al., 1994), the cell culture data (Ferri and Levitt, 1993), behavioral analysis of grafts (Barth and Stanfield, 1994), and other reports of early differences in the cerebral wall (Arimatsu et al., 1992; Dchay ct al., 1993; Kennedy and DeHay, 1993), strongly suggest that regional differences in the wall begin to emerge early (at least by E14 in our studies) and lead to the parcellated cerebral cortex hypothesized by Rakic (1988). Our studies suggest that these ventricular zone cells can be influenced by local environmental cues that move the population through specific periods of developmental restriction (Parnavelas et al.,1991; Levitt et al.,1993).

Response of grafted cortical cells depends on age of cells as well as phenotype examined

There are numerous factors involved in the determination of neuronal function and formation of cortical circuitry, each of which helps define the connections between a neuron and its targets. Target recognition and synaptogenesis are achieved through complex mechanisms (Sperry, 1963; Meinertzahagen, 1973, 1974; Trujillo-Cenoz and Melamed, 1973; Tomlinson and Ready, 1987; Grenningloh et al., 1991; Gölz et al., 1992; Kunes et al., 1993). In the mammalian cerebral cortex, the areal and laminar positions of a cortical neuron are generally predictive of where that neuron will send an axonal process (Jones, 1981). The time of origin of the neuron defines the laminar position (Angevine and Sidman, 1961; Rakic, 1974; Bayer and Altman, 1991) and the commitment to reside in a specific cortical layer (McConnell, 1985, 1988; McConnell and Kaznowski, 1991). The laminar cortical and subcortical projection patterns are subject to a wide variety of control mechanisms (Price and Blakemore, 1985; Killackey, 1990; Katz, 1991; Yamamoto, 1992; O'Leary and Koester, 1993). For example, the host environment can modulate the projection patterns of layer $V$ neurons in $E 17-$ 18 parietal and visual cortex transplanted heterotopically (Stanfield and O'Leary, 1985; O'Leary and Stanfield, 1989). Afferent thalamocortical fibers are able to control the expression of some features of cellular organization, such as the barrels in somatosensory cortex (Woolsey and Wann, 1976; Schlaggar and O'Leary, 1992). While these phenotypes appear highly plastic at later stages of fetal or postnatal rat development, when they are still forming, our transplantation data have focused on phenotypic features that develop earlier. Are these data consistent with each other? Suggestions have been made that the carly commitment by some cortical neurons to the limbic phenotype is due to a phylogenetically conserved parcellation of certain regions (O'Leary, 1989; Walsh, 1993). While the limbic system in general is considered highly conserved, association cortical areas, which include some of the limbic regions, change as dramatically in primates, where they are much more highly evolved, as do primary sensory and motor regions (Bayer, 1990; Killackey, 1990; Sur et al., 1990; Kaas, 1993). We have posed an alternate explanation to that of early developmental divergence of the different cortical divisions (Levitt et al., 1993). Occipital cortical grafts, from E17-E18 donors, showed an ability to respond to somatosensory environmental cues by forming barrels (Schlaggar and O'Leary, 1992). From our analysis of corticocortical and thalamocortical projections of limbic and sensorimotor grafts, we would predict that the visual cortex grafts, even 
at E17, might contain hybrid populations. At E17-E18, 50-70\% of the layer IV neurons have been generated in visual cortex (Miller, 1988), a consequence of the fact that the rodent cortex develops in a rostrocaudal and lateromedial gradient. Functional analyses of occipital transplants to rostral cortex indicate that indeed only a subpopulation of grafted neurons may be responding to the new environment, since somatosensory electrophysiological responses (Castro et al., 1991) and mediation of sensory behavior recovery by the occipital grafts (Barth and Stanfield, 1994) fail to occur. Our analysis of corticocortical connections of heterotopic grafts, with the tissue harvested at three different developmental ages, suggests that transplants containing a higher percentage of precursor cells will have a better chance of exhibiting phenotypic features most similar to the new host locale, and thus a better chance at possibly mediating meaningful functional recovery.

\section{Constraints on graft connectivity}

Our previous analysis of thalamocortical connections of tissue transplanted to perirhinal or somatosensory regions of the newborn rat brain indicated that different regions of the cortex are homogeneous early during development and that certain extrinsic factors in a host newborn cortical region are able to influence inncrvation patterns. For example, transplanting E12 presumptive sensorimotor tissue into neonatal limbic cortex resulted in the invasion of extensive limbic thalamic afferents (Barbe and Levitt, 1992b). It is interesting to note that more than $85 \%$ of the neurons in this heterotopic graft type expressed a limbicassociated molecule, LAMP (Barbe and Levitt, 1991). The E14 sensorimotor transplants, when placed into perirhinal cortex, contained a low pencentage of LAMP-positive neurons, but axons from the somatosensory ventrobasal complex failed to grow into these grafts. We suggested that this was due to the inability of the ventrobasilar thalamic axons in a neonatal rat, which normally are growing through the dorsal part of the internal capsule, to detect the presence of and grow toward tissue with sensorimotor-type molecular characteristics in the aberrant ventrolateral location. Upon entering the internal capsule, thalamic axons show little tendency to grow in the wrong direction (DeCarlos et al., 1992; Erzurumlu and Jhaveri, 1992). The limbic thalamic fibers from lateral dorsalis that project to frontal and anterior cingulate cortices (Domesick, 1969) and the somatosensory ventrobasal axons course under the region of all the grafts placed into the sensorimotor cortex. This location provides the thalamocortical afferents with direct access to the transplants. In the present study, the host contralateral perirhinal, anterior cingulate and somatosensory fibers have crossed the corpus callosum and some axons have entered the cortex at the time of transplantation (Wise and Iones, 1976; Ivy et al., 1979; Valentino and Jones, 1982; Jensen and Altman, 1992). All these contralateral corticocortical axons pass under the grafts placed into SmI cortex, thus providing them access to the transplants. In contrast, somatosensory callosal projections, like the somatosensory thalamocortical axons, do not course underneath the perirhinal cortex. Because of this, we limited our present analysis of corticocortical projections to grafts placed dorsally in somatosensory cortex, except for the very early E12 Sm into P transplants, in which we are able to manipulate the molecular phenotype of most of the cells. Here, limbic corticocortical projections were formed between the host and E12 Sm graft placed into the perirhinal location. We did perform a few El4 somatosensory transplants into perirhinal cortex, but retrogradely labeled callosal neurons were never seen, even with labeling times up to 10 weeks (data not shown). Again, we believe this is due to spatial constraints, preventing the somatosensory fiber system from growing toward the ventrolateral wall of the cerebral hemisphere, and the lack of recognition of the target cells.

In the present study, not all the afferents projecting into the grafts precisely match normal perirhinal or primary somatosensory cortical connections. For example, heterotopic grafts of E14 tissue from the rostral perirhinal cortex, placed into host sensorimotor cortex, reccive connections from not only the contralateral and ipsilateral anterior cingulate cortex, but also from the posterior cingulate cortex and sometimes the granular insular cortex. Guildin and Markowitsch (1983) showed that the rostral perirhinal cortex is part of the associative insular cortex in the rat, this area receiving projections from posterior cingulate, anterior cingulate cortices and granular and agranular insular cortices. Variations in the inputs into these grafts suggest some inconsistencies in our dissection techniques, so that grafts could include more caudal perirhinal cortex, and others, the rostral perirhinal cortex, which is part of a heterogeneous associative cortex. There does appear to be exuberance of the ipsilateral inputs into the E14 perirhinal grafts, probably due to the young age of the hosts at the time of analysis (P14), making interpretation difficult. However, when one compares the contralateral inputs of E14, E13, and E12 perirhinal tissues when transplanted into sensorimotor cortex, it becomes clear that the connections of the E14 grafts retain organizational features of their original areal location in the embryo as well as develop features characteristic of their new host locale. The E14 heterotopic perirhinal transplants have axonal projection patterns from both contralateral homotopic sensorimotor areas and contralateral limbic areas. The younger grafted tissue (E12 and E13) receives contralateral projections only from sensorimotor cortical areas. The limbic commissural inputs into the E14 P into Sm grafts may be exuberant inputs that have been maintained specifically into these grafts. We have begun analysis of grafts surviving long term (P65), using the same transplantation paradigm. These studies reveal thus far that the hybrid connections seen in the E14 heterotopically located Prh grafts are maintained into adulthood, with the presence of both sensorimotor and limbic thalamic and corticocortical inputs (Barbe, unpublished results). These results are buttressed by studies showing that the mature, restricted pattern of commissural projections in the rat is established between P7 and P15 (Wise and Jones, 1976; Ivy et al., 1979; Ivy and Killacky, 1981; Valentino and Jones, 1982), as well as a recent study by Ebrahimi-Gaillard et al. (1994), in which occipital cortex transplanted into frontal cortex projected to host targets in a hybrid pattern that was characteristic of both donor and host cortical regions.

In conclusion, short term survival of aged E14 grafts, which contain over 50\% LAMP expressing neurons (Barbe and Levitt, 1991), receive cortical as well as thalamic (Barbe and Levitt, $1992 b$ ) inputs that are hybrid in nature. Perhaps the early expression of LAMP in limbic cortical neurons, at or after neurons become postmitotic (Barbe and Levitt, 1991; Ferri and Levitt, 1993), reflects a specific developmental path taken by neurons along which the expression of other limbic characteristics will follow. Thus, the fating and ultimate commitment of neurons to this molecular phenotype may be important in determining the connectivity and function of cerebral cortical neurons. 


\section{Appendix}

\section{Abbreviations}

$\mathrm{ACg} 1,2$ anterior cingulate cortex parts 1,2

AI agranular insular cortex

cc corpus callosum

Ent entorhinal cortex

FL forelimb

Frl frontal motor cortex area 1

Fr2 frontal motor cortex area 2

GI granular insular cortex

HL hindlimb

Uc or Ucc occipital cortex

$\mathbf{P}$ or Prh perirhinal cortex

$\mathrm{PCg} 1$ agranular posterior cingulate cortex

$\mathrm{PCg} 2$ granular posterior cingulate

Prh perirhinal cortex

Pyr prepiriform cortex

SII secondary somatosensory cortex

Sm primary sensorimotor cortex, also known as Par1, SI, and primary somatosensory area

SmI primary sensorimotor cortex

$\mathrm{Te} 1,2,3$ auditory cortex, area temporalis

th thalamus

\section{References}

Akers RA, Killackey HP (1978) Organization of corticocortical connections in the parietal cortex of the rat. J Comp Neurol 181:513538

Altman J, SA Bayer (1990) Vertical compartmentation and cellular transformation in the germinal matrices of the embryonic rat cerebral cortex. Exp Neurol 107:23-35.

Angevine JB, Sidman FB (1961) Autoradiographic study of cell migration during histogenesis of cerebral cortex in the mouse. Nature 192:766-768.

Arimatsu Y, Miyamoto M, Nihonmatsu I, Hirata K, Uratani U, Hatanaka U, Takiguchi-Hayshi K (1992) Early regional specification for a mo lecular neuronal phenotype in the rat neocortex. Proc Natl Acad Sci USA 89:8879-8883.

Baier H, Bonhoeffer F (1992) Axon guidance by gradients of a targetderived component. Science 255:472-475.

Barbe M, Levitt P (1991) The early commitment of fetal neurons to limbic cortex. J Neurosci 11:519-533.

Barbe MF, Levitt P (1992a) Disruption in vivo of the developing hippocampal mossy fiber circuit by antibodies of the limbic system associated membrane protein. Soc Neurosci Abstr 18:38.

Barbe M, Levitt P (1992b) Attraction of specific thalamic input by cerebral grafts depends on the molecular identity of the implant. Proc Natl Acad Sci USA 89:3706-3710.

Barth TM, Stanfield BB (1994) Homotopic but not heterotopic fetal cortical transplants can result in functional sparing following neonatal damage to the frontal cortex in rats. Cereb Cortex 4:271-278.

Bayer SA (1990) Development of the lateral and medial limbic cortices in the rat in relation to cortical phylogeny. Exp Neurol 107:118131.

Bayer SA, Altman J (1991). Neocortical development. New York: Raven.

Callaway EM, Katz LC (1990) Emergence and refinement of clustered horizontal connections in cat striate cortex. J Neurosci 10:1134-1153.

Castro AJ, Hogan TP, Sorensen JC, Klausen BS, Danielsen EH, Zimmer J, Neafsey EJ (1991) Heterotopic neocortical transplants. An anatomical and electrophysiological analysis of host projections to occipital cortical grafts placed into sensorimotor cortical lesions made in newborn rats. Dev Brain Res 58:231-236.

Caviness VS, Rakic P (1978) Mechanisms of cortical development: a view from mutations in mice. Annu Rev Neurosci 1:297-326.

Chalupa LM, Killackey HP (1989). Process elimination underlies ontogenetic change in the distribution of callosal projection neurons in the postcentral gyrus of the fetal rhesus monkey. Proc Natl Acad Sci USA 86:1076-1079.

Cohen-Tannoudji M, Babinet C, Wassef M (1994) Early determination of a mouse somatosensory cortex marker. Nature 368:460-463.

Deacon TW, Eichenbaum H, Rosenberg P, Eckmann K (1983) Afferent connections of the perirhinal cortex in the rat. J Comp Neurol 220: $168-190$.
DeCarlos JA, O'Leary DDM (1992) Growth and targeting of subplate axons and establishment of major cortical pathways. J Neurosci 12 : $1194-1211$

Dehay C, Giroud P, Berland M, Smart I, Kennedy H (1994) Modulation of the cell cycle contributes to the parcellation of the primate visual cortex. Nature 336:464-466.

Domcsick VB (1969) Projections from the cingulate cortex in the rat Brain Res 12:296-320.

Donoghue JP, Wise SP (1982) The motor cortex of the rat: cytoarchitecture and microstimulation mapping. J Comp Neurol 212:76-88.

Donoghue JP, Kerman KL, Ebner FF (1979) Evidence for two organizational plans within the somatic sensory-motor cortex of the rat. J Comp Neurol 183:647-664.

Ebrahimi-Gaillard A, Guitet J, Garnier C, Roger M (1994) Topographic distribution of efferent fibers originating from homotopic or heterotopic transplants: heterotopically transplanted neurons retain some of the developmental characteristics corresponding to their site of origin. Dev Brain Res 77:271-283.

Elberger AJ. (1994) Transitory corpus callosum axons projecting throughout developing rat visual cortex revealed by DiI. Cereb Cortex 4:279-299.

Erzurumlu RS, Jhaveri S (1992) Emergence of connectivity in the embryonic rat parietal cortex. Cereb Cortex 2:336-352.

Ferri RT, Levitt P (1993) Cerebral cortical progenitors are fated to produce region-specific neuronal population. Cereb Cortex 3:187198.

Fraser SE (1980) A differential adhesion approach to the patterning of nerve connections. Dev Biol 79:453-464.

Ghosh A, Shatz CJ (1993) A role of subplate neurons in the patterning of connections from thalamus to neocortex. Development 117:10311047

Ghosh A, Antonini A, McConnell SK, Shatz CJ (1990) Requirement for subplate neurons in the formation of thalamocortical connections. Nature 347:179-181.

Gierer A (1987) Direction cues for growing axons forming the retinotectal projection. Development 101:479-489.

Godement P, Vanselow H, Thanos S, Bonhoeffer F (1987) A study in developing visual system with a new method of staining neurons and their processes in fixed tissue. Development 101:695-713.

Gölz M, Novak N, Bastmeyer M, Bolz J (1992). Membrane bound molecules on rat cerebral cortex regulate thalamic innervation. Development 116:507-519.

Grenningloh G, Rehm J, Goodman CS (1991) Genetic analysis of growth cone guidance in Drosophila: fasciculin II functions as a neuronal recognition molecule. Soc Neurosci Abstr 17:910.

Guildin WO, Markowitsch HJ (1983) Cortical and thalamic afferent connections of the insular and adjacent cortex of the rat. J Comp Neurol 215:135-153.

Hall RD, Lindholm EP (1974) Organization of motor and somatosensory neocortex in the albino rat. Brain Res 66:23-28.

Hankin MH, Lund RD (1987) Role of the target in directing the outgrowth of retinal axons: transplants reveal surface-related and surface-independent cues. J Comp Neurol 263:455-466.

Harris WA (1989) Local positional cues in the neuroepithelium guide retinal axons in embryonic Xenopus brain. Nature 339:218-221.

Heffner CD, Lumsden AGS, O'Leary DDM (1990) Target control of collateral extension and directional axons growth in the mammalian brain. Science 247:217-220.

Hernit CS, Van Sluyters RC, Murphey KM (1990) Visual callosal development in neonatal rats: do migrating or undifferentiating cells have an interhemispheric axon. Soc Neurosci Abstr 16:803.

Hicks SP, D'Amato CJ (1963) Cell migration to the isocortex in the rat. Anat Rec 160:619-634.

Horton HL, Levitt P (1988) A unique membrane protein is expressed on early developing limbic system axons and cortical targets. J Neurosci 8:4653-4661.

Ivy GO, Akers RM, Killackey HP (1979)Differential distribution of callosal projection neurons in the nconatal and adult rat. Brain Res 173:532-537.

Jacobson S (1970) Distribution of commissural axon terminals in the rat neocortex. Exp Neurol 28:193-205.

Jensen KF, Killackey HP (1984) Subcortical projections from ectopic neocortical neurons. Proc Natl Acad Sci USA 81:964-968.

Jones EG (1981) Anatomy of cerebral cortex: columnar input-output organization. In: The organization of the cerebral cortex (Schmitt FO, 
Worden FG, Adelman G, Dennis SG, eds), pp 199-235. Cambridge MA: MIT Press.

Kaas JH (1993) Evolution of multiple areas and modules within neocortex. Perspect Dev Neurobiol 1:101-107.

Katz LC (1991) Specificity in the development of vertical connections in cat striate cortex. Eur J Neurosci 3:1-9.

Keller F, Rimwall K, Barbe MF, Levitt P (1989) A membrane glycoprotein associated with the limbic system mediates the formation of the septo-hippocampal pathway in vitro. Neuron 3:551-561.

Kennedy H, Dehay C (1993) The importance of developmental timing in cortical specification. Perspectives on developmental neurobiology $1: 93-99$.

Killackey HP (1990) Neocortical expansion: an attempt toward relating phylogeny and ontogeny. J Cognit Neurosei 2:1-17.

Killackcy HP, Chalupa LM (1986) Ontogenetic changes in the distribution of callosal projection neurons in the postcentral gyrus of the fetal rhesus monkey. J Comp Neurol 244:331-348.

Kretteck JE, Price JL (1977) The cortical projections of the mediodorsal nucleus and adjacent thalamic nuclei in the rat. J Comp Neurol 171:157-191.

Krieg WJS (1946) Connections of the cerebral cortex. I. The albino rat. A. Topography of the cortical areas. J Comp Neurol 84:221-275.

Kunes S, Wilson C, Steller H (1993) Independent guidance of retinal axons in the developing visual system of Drosophila. J Neurosci 13: 752-767.

Lemmon V, Pearlman AL (1981) Does laminar position determine the receptive field properties of cortical neurons? A study of corticotectal cells in area 17 of the normal mouse and the reeler mutant. J Neurosci 1:83-93.

Levitt P (1984) A monoclonal antibody to limbic system neurons. Science 223:229-301.

Levitt P, Ferri RT, Barbe MF (1993) Progressive acquisition of cortical phenotypes as a mechanism for specifying the developing cerebral cortex. Perspect Dev Neurobiol 1:65-74

Lumsden AGS, Davies AM (1983) Earliest sensory nerve fibers are guided to peripheral targets by attractants other than nerve growth factor. Nature 306:786-788.

McConnell SK (1988) Fates of visual cortical neurons in the ferret after isochronic and heterochronic transplantation. J Neurosci 8:945974.

McConnell SK, Kaznowski CE (1991) Cell cycle dependence of laminar determination in developing cerebral cortex. Science 254:282285.

McConnell SK, Ghosh A, Shatz CJ (1989) Subplate neurons pioneer the first axon pathway from the cerebral cortex. Science 245:978893

Meinertzhagen IA (1973) Development of the compound eye and occipital lobes of insects. In: Developmental neurobiology of arthropods (Young D, ed), pp 52-104. London: Cambridge UP.

Meinertzhagen IA (1974) The development of neuronal connection patterns in the visual system of insects. In: Ciba Foundation symposium 29, Cell patterning, pp 265-258. New York: Elsevier.

Miller M (1988) Development of projection and local circuit neurons in neocortex. In: Cerebral cortex, Vol 7, Development and maturation of cerebral cortex (Peters A, Jones EG, eds), pp 133-175. New York: Plenum.

O'Leary DDM (1989) Do cortical areas emerge from a protocortex. Trends Neurosci 12:400-406.

O'Leary DDM, Koester SE (1993) Development of projection neuron types, axon pathways, and patterned connections of the mammalian cortex. Neuron 10:991-1006.

O'Leary DDM, Stanfield BB (1989) Selective elimination of axons extended by developing cortical neurons is dependent on regional locale: experiments utilizing fetal cortical transplants. J Neurosci 9:2230-2246.

O'Leary DDM, Bicknese AR, De Carlos JA, Heffner CD, Koester SE, Kutka LJ, Terashima T (1990) Target selection by cortical axons: alternative mechanisms to establish axonal connections in the developing brain. Cold Spring Harbor Symp Quant Biol 55:453-468.

Parnavelas JG, Barfield JA, Franke E, Luskin MB (1991) Separate progenitor cells give rise to pyramidal and nonpyramidal neurons in the rat telencephalon. Cereb Cortex 1:463-468.

Paxinos G, Watson C (1986) The rat brain in stereotaxic coordinates. Sydney: Academic.
Paxinos G, Tork I, Tecott LH, Valentino KL (1991) Atlas of the developing rat brain. San Diego: Academic.

Pimenta AF, Zhukareva V, Reinoso B, Grimley C, Fischer I, Levitt P (1993) Cloning the limbic system-associated membrane protein (LAMP): a new immunoglobulin superfamily member. Soc Neurosci Abstr 19:689.

Placzek M, Tessier-Lavigne N, Yamada T, Dodd J, Jessel TM (1990) Guidance of developing axons by diffusible chemoattractants. Cold Spring Symp Quant Biol 55:279-289.

Price DJ, Blakemore C (1985) Regressive events in the postnatal development of associated projections in the visual cortex. Nature 316 : 721-724.

Quinn B, Weber E (1988) $m$-Phenylenediamine: a novel fluorescent nissl-like stain of neuroanatomy. Soc Neurosci Abstr 14:547.

Rakic P (1974) Neurons in rhesus monkcy visual cortex: systematic relation between time of origin and eventual disposition. Science 183: $425-427$.

Rakic P (1988) Specification of cerebral cortical areas. Science 241: 170-176.

Rose M (1929) Cytoarchitektonisher Atlas der Grosshirnrin de der Maus. J Psychol Neurol 40:1-51.

Sanderson KJ, Welker W, Shambes GM (1984) Reevaluation of motor cortex and sensorimotor overlap in cerebral cortex of albino rats. Brain Res 292:251-260.

Schalggar BL, O'Leary DDM (1992) Potential of visual cortex to develop an array of functional units unique to somatosensory cortex. Science 252:1556-1559.

Schwartz ML, Rakic P, Goldman-Rakic PS (1991) Early phenotype expression of cortical neurons: evidence that a subclass of migrating neurons have callosal axons. Proc Natl Acad Sci USA 88:1354-1358.

Simon DK, O'Leary DDM (1992a) Responses of retinal axons in vivo and in vitro to position-encoding molecules in the embryonic superior colliculus. Neuron 9:977-989.

Simon DK, O'Leary DDM (1992b) Influence of position along the medial-lateral axis of the superior colliculus on the topographic targeting and survival of retinal axons. Dev Brain Res 69:167-172.

Sperry RW (1963) Chemoaffinity in the orderly growth of nerve fiber patterns and connections. Proc Natl Acad Science USA 78:21452149.

Stahl B, Muller B, Boxberg Y, Cox E, Bonhoeffer F (1990) Biochemical characteristics of a putative axonal guidance molecule of the chick visual system. Neuron 5:735-743.

Stanfield BB, O'Leary DDM (1988) Neurons in the rat subiculum with transient postmamillary collateral during development maintain projections to the mamillary complex. Exp Brain Res 72:185-190.

Stanfield BB, O'Leary DDM (1985) The transient corticospinal projection from the occipital cortex during the postnatal development of the rat. J Comp Neurol 238:236-248.

Stanfield BB, O'Leary DDM, Fricks C (1982) Selective collateral elimination in early postnatal development restricts cortical distribution of rat pyramidal tract neurons. Nature 298:371-372.

Stanfield BB, Nahin BR, O'Leary DDM (1987) A transient postmamillary component of the rat fornix during development: implications for interspecific differences in mature axonal projection. J Neurosci 7:3350-3361

Sur M, Pallas SL, Roe AW (1990) Cross-modal plasticity in cortical development: differentiation and specification of sensory neocortex. Trends Neurosci 13:227-233.

Tessier-Lavigne M, Placzek M, Lumsden AGS, Dodd J, Jessell T (1988) Chemotropic guidance of developing axons in the mammalian central nervous system. Nature 236:775-778.

Iomlinson A, Ready DF (1987) Cell fate in the Drosophila ommatidium. Dev Biol 193:264-275.

Trujillo-Cenoz O, Melamed J (1973) The development of retina-lamina complex in muscoid flies. J Ultrastruct Res 42:554-581.

Walsh C (1993) Cell lineage and regional specification in the mammalian neocortex. Perspect Dev Neurobiol 1:75-80.

Walter J, Kern-Veits B, Huf J, Stolze B, Bonhoeffer F (1987) Recognition of position-specific properties of tectal cell membranes by retinal axons in vitro. Development 101:685-696.

Wise SP, Jones EG (1976) The organization and postnatal development of the commissural projections of the somatic sensory cortex of the rat. J Comp Neurol 168:313-343.

Wise SP, Jones EG (1978) Developmental studies of thalamocortical 
and commissural connections in the rat somatic sensory cortex. I Comp Neurol 178:187-208.

Woolsey TA, Wann JR (1976) Areal changes in mouse cortical barrels following vibrissal damage at different postnatal ages. J Comp Neurol 170:53-66.

Valentino KL, Jones EG (1982) The early formation of the corpus callosum: a light and electron microscopic study in foetal and neonatal rats. J Neurocytol 11:538-609.

Vogt BA, Miller MW (1981) Cortical connections between rat cingulate cortex and visual, motor, and postsubicular cortices. J Comp Neurol 216:192-210.

Yamamoto M, Kurotoni T, Toyamak K (1989) Neural connections between lateral geniculate nucleus and visual cortex in vitro. Science 245:192-194.

Yamamoto N, Yamada K, Kurotani T, Toyama K (1992) Laminar specificity of extrinsic cortical connections studied in coculture preparations. Neuron 9:217-228.
Thukareva V, I evitt P (1993) Homophilic binding and phosphatidyl inositol linkage of the limbic system associated membrane protein (LAMP) are consistent with a role in specific recognition events in the developing brain. Mol Biol Cell 3:197a.

Ziles K (1985) The cortex of the rat: a stereotaxic atlas. Berlin: Springer.

Ziles K (1990) Amalomy of the neocortex: cytoarchitecture and myeloarchitecture. In: The cerebral cortex of the rat, pp 77-112. Cambridge, MA: MIT Press.

Ziles K, Wree A (1985) Cortex: areal and laminar structure. In: The rat nervous system, Vol 1 (Paxinos G, ed). Sydney: Academic.

Ziles K, Ziles B, Schleicher A (1980) A quantitative approach to cytoarchitectonics. VI. The area pattern of the cortex in the albino rat. Anat Embryol 159:335-360.

Ziles K, Armstrong E, Gottsfried S, Schleicher A (1986) Ouantitative cytoarchitectonics of the posterior cingulate cortex in primates. $J$ Comp Neurol 253:514-524. 